$2 \operatorname{cog} 2$

UCR L-20350

RECEIVED BY DTE KAR 29.997

\title{
CREEP OF LITHIUM FLUORIDE SINGLE CRYSTALS AT \\ ELEVATED TE:MPERATURES
}

Donald R. Cropper

(Ph.D. Thesis)

January 1971

AEC Contract No. W-7405-eng-48

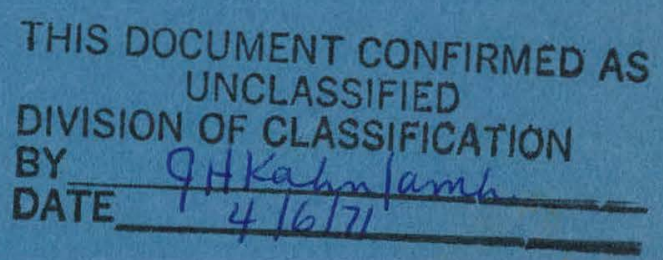

.

$\mathcal{1}$

LAWRENCE RADIATION LABORATORY UNIVERSITY of CALIFORNIA BERKELEY 


\section{DISCLAIMER}

This report was prepared as an account of work sponsored by an agency of the United States Government. Neither the United States Government nor any agency Thereof, nor any of their employees, makes any warranty, express or implied, or assumes any legal liability or responsibility for the accuracy, completeness, or usefulness of any information, apparatus, product, or process disclosed, or represents that its use would not infringe privately owned rights. Reference herein to any specific commercial product, process, or service by trade name, trademark, manufacturer, or otherwise does not necessarily constitute or imply its endorsement, recommendation, or favoring by the United States Government or any agency thereof. The views and opinions of authors expressed herein do not necessarily state or reflect those of the United States Government or any agency thereof. 


\section{DISCLAIMER}

Portions of this document may be illegible in electronic image products. Images are produced from the best available original document. 


\section{PAGES $\mathrm{i}$ to $\mathrm{ii}$ WERE INTENTIONALLY LEFT BLANK}


-iv-

Page

v. CONCLUSIONS

51

ACKN OWLEDGMENTS

53

REFE REN CES

54 


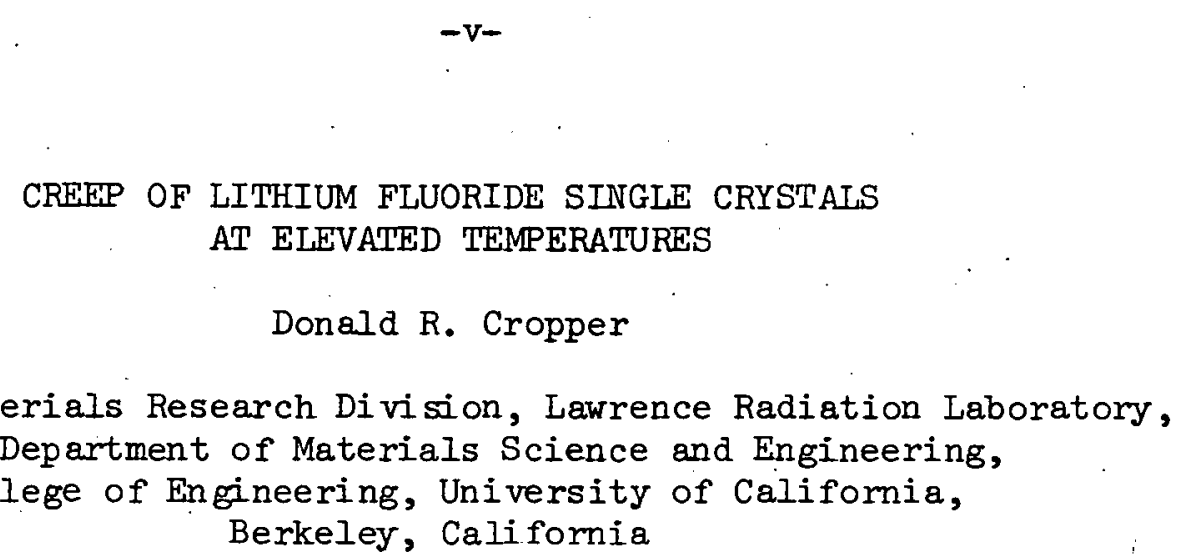

ABSTRACT

The creep deformation of lithium fluoride single crystals was studied in compression over the temperature range $650^{\circ}-750^{\circ} \mathrm{C}\left(0.8-0.9 \mathrm{~T}_{\mathrm{m}}\right)$. Extended primary creep was observed for crystals deformed with the compression axis in $\langle 100\rangle$ orientation; strains of 0.20 or more were required for the establishment of steady-state conditions. Crystals with compression axes in the <lll> direction reached steady-state quickly, at strains. of 0.05 or less. The steady-state strain rate was found to be proportional to the stress raised to the power $n$, where $n$ ranged from 3.1 for <1l1> crystals to 4.1 for <100> crystals. The activation energy for creep was determined to be $53 \pm 7 \mathrm{kcal} / \mathrm{mole}$ over the temperature range considered, regardless of crystal orientation or impurity content up to $300 \mathrm{ppm}$ total impurities; this compares favorably with the activation energy for lattice diffusion of the fluorine ion in LiF. Well developed substructures were observed in the deformed crystals with the subgrain diameter varying inversely with the applied stress. These results suggest that the creep deformation of lithium fluoride single crystals may be similar to that for metals and is probably dependent lipon the dislocation climb process. 


\section{INTRODUCIION}

While the mechanical behavior of ionic crystals has been the subject of intensive study during recent years, there is surprisingly little information in the literature on the high temperature creep behavior of such materials. Creep is usually defined as the continued deformation of a material at a constant stress and temperature, and is characterized by the general features shown in Fig. I. The curve labeled A is representative of creep at relatively low temperatures, usually $<0.5 \mathrm{Tm}$, and is normally referred to as transient or logrithmic creep. Here the instantaneous strain rate, $\dot{\varepsilon}$, continuously decreases with time until no further deformation is observed. At somewhat higher temperatures, normally $>0.5 \mathrm{Tm}$, creep behavior is usually characterized by curves similar to that labeled B. Here the period of decreasing $\dot{\varepsilon}$ (region I), called the primary creep period is followed by a period of constant strain rate (region II). The strain rate in this period, $\dot{\varepsilon}_{s}$ is referred to as the steady-state or minimum creep rate. Under certain conditions steady-state (region II) creep may occur without a primary or transient creep period. The steady-state strain rate is then reached immediately on application of the stress. A period of increasing strain rate (region III) is often observed for tensile creep tests and is usually terminated by fracture of the creep specimen.

\section{A. Analysis of Creep Deformation}

Most studies of creep deformation are confined to measurements made in region II, under "steady state" creep conditions. Here the observed rate of deformation may be envisioned as a balance between the work hardening induced by continued deformation and the recovery processes 


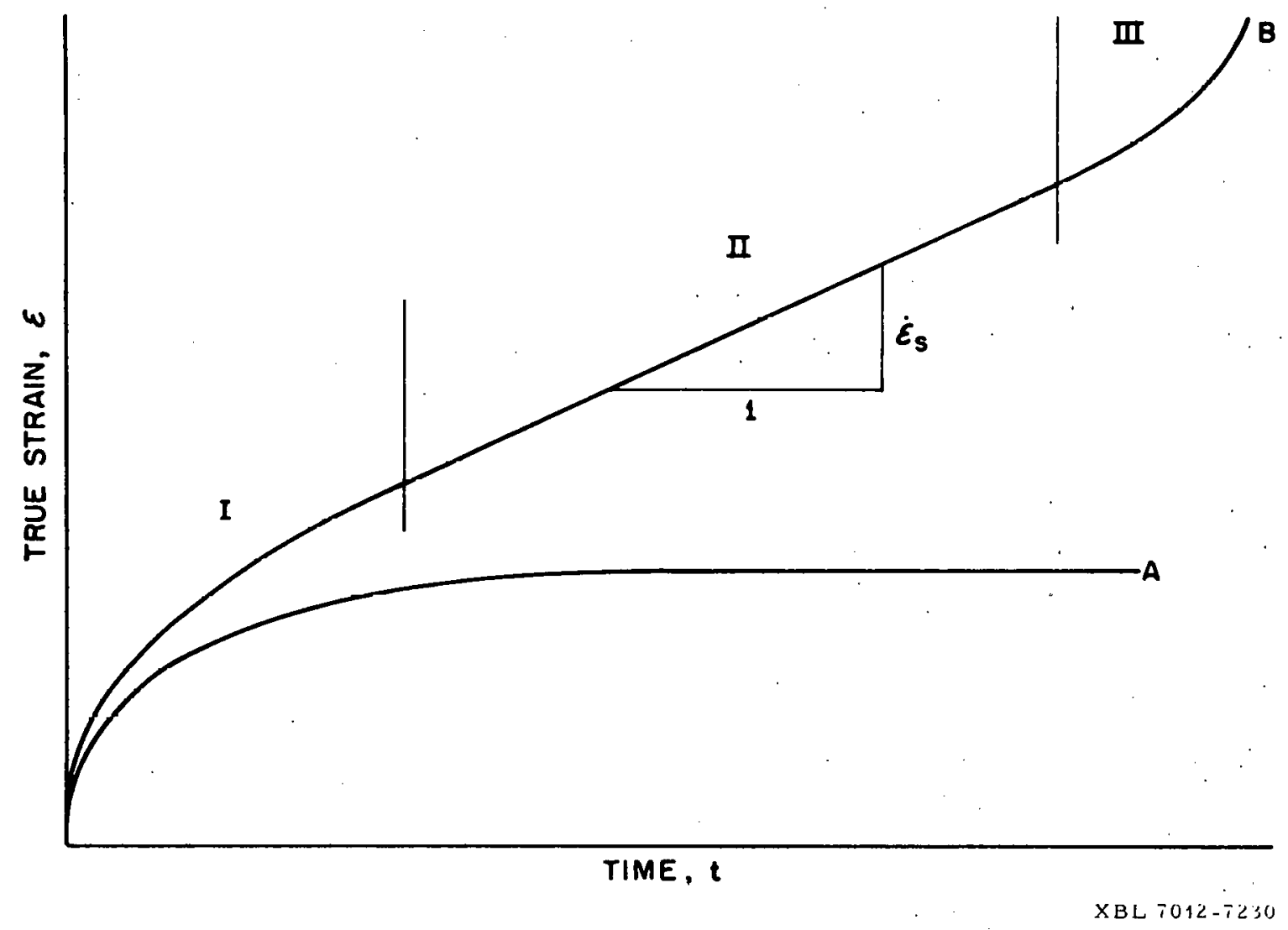

Figure 1. Idealized creep curves. 
operative at high temperatures.

The various theoretical models describing steady-state creep were recently reviewed by Mukherjee, Bird and Dorn ${ }^{1}$ who concluded that in the regime of high temperatures $(>0.5 \mathrm{Tm})$ and intermediate stresses where dislocation processes are likely to dominate deformation behavior, the best description of creep is given by an expression of the form

$$
\dot{\varepsilon}=\mathrm{A} \frac{\mathrm{Gb}}{\mathrm{kT}}\left(\frac{\sigma}{\mathrm{G}}\right)^{\mathrm{n}} \mathrm{D}
$$

where $\dot{\varepsilon}$ is the steady-state creep rate, $G$ is the shear modulus, $b$ is the Burgers vector, $\mathrm{k}$ is the Boltzmann constant, $\mathrm{T}$ is the absolute temperature, $\sigma$ is the applied stress, $D$ is the diffusivity, and $A$ and $n$ are dimensionless constants. The diffusivity term $D$, being of the form

$$
D=D_{0} e^{-Q} c^{/ R T}
$$

contains the temperature dependence of the creep rate; the activation energy for creep $Q_{c}$ has been shown to accurately agree with the activation energy for self diffusion when the temperature dependence of the shear modulus $G$ is taken into account in Eq. (1).

Many workers approximate the relationship between creep rate, stress and temperalure by a phenomenological expression of the form

$$
\dot{C}=A^{\prime} \sigma^{n} e^{-Q / R T}
$$


which; as shown by Mukherjee et al. ${ }^{2}$ is neither dimensionally nor experimentally correct. Nevertheless, the values of $n$, the stress exponent and the apparent activation energy, $Q$, are frequently presented as evidence that a particular mechanism is the rate controlling step for creep. In many cases, agreement between directly measured $Q$ values and self-diffusion activation energies are satisfactory; however, Mukherjee et al. ${ }^{2}$ have shown that in metallic systems the agreement is improved when $Q_{C}$.is calculated in terms of the parameters of $\mathrm{Eq}$. (1). It is suggested, therefore, that studies of creep deformation in non-metallic systems for which shear modulus data are available be presented in terms of Eq. (1), if applicable. This procedure facilitates comparison of the behavior of metallic and non-metallic materials.

\section{B. Creep of Ionic Materials}

The majority of creep measurements reported in the literature on ionic solids have been made on $\mathrm{NaCl}$. The single crystal compression measurements of Christy, ${ }^{3}$ Geguzin et al., 4 Ilschner and Reppich, ${ }^{5}$ Blum and Ilschner, and Schuh, Blum and Ilschner ${ }^{7}$ all result in a power law stress dependence of the steady state strain rate with $n \approx 4-5$. Activation energy values are not as consistent with a reported range from $246 \mathrm{kcal} / \mathrm{mole}$ to $\sim 82.4 \mathrm{kcal} / \mathrm{mole}$. In fine-grained $\mathrm{NaCl}$ polycrystals, tested in bending, Kingery and Montrone 8 observed "viscous deformation" at high temperatures, i.e., strain rate directly proportional to stress and to the diffusivity of the $\mathrm{Cl}^{-}$ion. In contrast, Burke ${ }^{9}$ found a power law relationship for coarse-grained $\mathrm{NaCl}$ deformed in compression with a stress exponent of $n=5.0$. He obtaincd an activation energy value of $49 \mathrm{kcal} / \mathrm{mole}$ at high temperatures in good agreement with that 
: for $\mathrm{Cl}^{-}$ion lattice diffusion in $\mathrm{NaCl}$. LeConte ${ }^{10}$ measured activation energies for creep in polycrystalline $\mathrm{NaCl}$ in compression and found an increase in $Q$ with temperature from $12.5 \mathrm{kcal} / \mathrm{mole}$ at $29^{\circ} \mathrm{C}$ to $30 \mathrm{kcal} /$ mole at $300^{\circ} \mathrm{C}$.

Other studies on creep behavior in ionic materials include the early work of Christy ${ }^{l}$ on $\mathrm{AgBr}$ single crystals in which a $Q$ somewhat higher than self diffusion activation energies for either ionic species was measured. Recently Cannon and Sherby ${ }^{12}$ conducted creep studies in compression on polycrystalline $\mathrm{NaCl}-\mathrm{KCl}$ solid solutions and found the steady-state creep rate to be proportional to the third power of the stress and to the diffusion coefficient of the cation. Pure polycrystalline $\mathrm{KCl}$ was found to obey an $\mathrm{n}=5$ power law.

Polycrystalline LiF has been studied under compressive creep conditions. by Cropper and Langdon ${ }^{13}$ who found a power law. stress dependence with $n=6.6$ and an activation energy of $50.1 \mathrm{kcal} / \mathrm{mole}$ in good agreement with that for $\mathrm{F}^{-}$diffusion in the intrinsic range. A study of the correlation between activation energies for creep, fracture and sublimation by Betekhtin and Bakhtiboev ${ }^{14}$ was made from creep measurements on ivacl, $\mathrm{KCl}$ and LiF single crystals. They concluded that the stress dependence of the steady-state strain rate was logarithmic, i.e, $\dot{\varepsilon} \alpha e^{B \sigma}$ and obtained an activation energy value of $\sim 70 \mathrm{kcal} / \mathrm{mole}$ for $\mathrm{LiF}$.

The purpose of the present investigation is to expand creep measurements on ionic single crystals to the LiF system at high temperatures. An attempt is made to deduce the particular rate controlling mechanism for creep in the limited range of temperatures and stresses considered, and the results are compared to those obtained under similar conditions 
$-6-$

for other materials. 
II. EXPERIMENTAL PROCEDURE

A. Materials

Lithium fluoride single crystals were purchased from the Harshaw Chemical Company, Cleveland, Ohio, as cleaved blanks nominally 1 inch by 1 inch by $1 / 4$ to $5 / 16$ inch thick. Three different commercial grades were obtained, henceforth to be referred to as monochromator quality (Mono.), infra-red quality (I.R.), and vacuum ultra-violet quality (U.V.), in increasing degree of purity. Spectrographic analysis was employed to identify the principal cation impurities present, summarized in Table I. Detection limits are indicated by the numbers in parentheses following each element. From these results, the major difference between the three grades of material appears to be the presence of $300 \mathrm{ppm} \mathrm{Mg}$ in the monochromator quality crystals.

Table I. Cation impurities in ppm."

\begin{tabular}{ccccc}
\hline Element & Mono. & I.R. & U.V. \\
\hline Magnesium (5) & 300 & $\sim 5$ & $\sim 5$ \\
Calcium (3) & $\sim 5$ & $\sim 10$ & $\sim 6$ \\
Copper (2) & $<2$ & $\sim 2$ & $<2$ \\
\hline \hline
\end{tabular}

* Determined by American Spectrographic Laboratories, Inc., San Francisco, California.

Specimens for creep tests were prepared by sawing with a small resin bunded liminend impregnated blade. Cryatals to be deformed with the applied stress parallel to $\langle 100>$ were easily obtained by making cuts parallel to the $\{100\}$ cleavage faces of the blanks. These specimens, 
henceforth referred to as <100> crystals were right rectangular parallelepipeds normally $7 / 16$ to $1 / 2$ inch long and $1 / 4$ to $5 / 16$ inch thick. Length to thickness ratios of the majority of the <100> crystals thus ranged from 1.5 to 2.0. A limited number of $\langle 100\rangle$ specimens were prepared in the form of cubes, i.e., with length to thickness ratios of $\sim_{1} .0$.

Crystals to be deformed with the applied stress parallel to <lll> were cut from cubes of <100> oriented crystals using a procedure similar to that described previously for $\mathrm{MgO}$ by Ilulse et al. $\left.{ }^{15} \mathrm{~A}<100\right\rangle$ cube was cemented to a jig machined from bakelite such that the <lll> axis of the cube was parallel to the diamond saw blade. Two identical resin bonded blades separated by a spacer were then employed to make two pairs of parallel cuts at right angles resulting in a prism with square crosssection and a $\langle 111\rangle$ axis. Due to the limitation of a $5 / 16$ inch maximum thickness of the original cubes, the <lll> specimens were necessarily smaller than the <lo thick. These crystals were then cut to the appropriate length to obtain length to thickness ratios between 1.5 and 2.0 .

After cutting to the appropriatc dimensions, all specimens were mounted in a special $j i g$ and sanded on both ends with "O" grade emery polishing paper to insure that the ends were flat, parallel to each other and perpendicular to the loading axis. Prior to testing, each crystal, was polished for $1 / 2$ hour in $85 \% \mathrm{H}_{3} \mathrm{PO}_{4}$ at $100-120^{\circ} \mathrm{C}$ to remove the surface damage incurred in cutting. Masking lacquer was used to protect the ends of the specimens from attack during the chemical polish in order to maintain flatness. Disappearance of birefringence effects from the crystals after chemical polishing confirmed the removal of the 
damaged surface laver.

\section{B. Apparatus}

Specimens were tested in compression in a small dead-load testing

machine similar to that described by Sherby. ${ }^{16}$ The total strain was continuously measured by a linear variable differential transformer and recorded by a recording potentiometer. Overall strain sensitivity was $\pm 5 \times 10^{-5}$. Elevated temperatures were obtained by a small resistance furnace positioned around the specimen and were constant to within $\pm 1^{\circ} \mathrm{C}$ of the reported values.

\section{Creep Tests}

Specimens were placed between two $99.5 \% \mathrm{Al}_{2} \mathrm{O}_{3}$ buttons for creep testing to protect them from contact with the stainless steel loading platens. A 0.0005 inch thick platinum foil between the LiF crystal and the $\mathrm{Al}_{2} \mathrm{O}_{3}$ buttons acted as a lubricant and allowed the crystal ends to spread during the course of a test, thus essentially eliminating barreling which frequently occurs in specimens tested in compression. Those portions of the Pt foil extending outward from beneath the LiF crystals were observed to undergo some chemical attack, particularly after tests at higher temperatures and long times. A yellow-green powdery residue was often observed around the edges of the crystal while the crystal itself remained colorless and apparently free from contamination. The major portion of the Pt foil between the LiF crystal and the $\mathrm{Al}_{2} \mathrm{O}_{3}$ button was not attacked. Test temperatures $\left(650^{\circ}-750^{\circ} \mathrm{C}\right.$ ) were reached after heating for four to six hours, and specimens were normally held at temperature for several hours prior to applying the load. 
The majority of the creep tests were performed at a single stress and temperature. To insure that a constant stress was maintained throughout the test, additional pre-determined load increments were added at engineering strain intervals of 0.01 to compensate. for the increase in cross-section with compressive strain. Initially these increments were calculated by assuming constancy of volume and neglecting any barreling that may have occurred. Subsequently, as the number of crystals tested increased, it was possible to develop an empirical correction based on the actual change in cross-section as a function of strain.

A small number of crystals were subjected to "incremental" creep tests, i.e., tested at a constant temperature and a number of different stresses or alternatively deformed under a constant stress while the. temperature was cycled over a narrow range. This approach attempts to minimize experimental scatter between specimens for the evaluation of stress and temperature dependence of the creep rate.

\section{Microstructural Observations}

After deformation, specimens were prepared for microstructural observations by sectioning with a resin bonded diamond blade. The crystals were mounted in plastic and polished through "4-0" emery polishing paper followed by polishing with Linde $A$ in water. A chemical polish in a $2 \%$ solution of $\mathrm{NH}_{4} \mathrm{OH}$ in distilled water at room temperature was used to remove the surface layers containing damage from the mechanical polishing. Finally, the crystals were etched in a solution of $4 \% \mathrm{HBF}_{4}$ in 200 proof ethyl alcohol which. was shown by Scott and Pask ${ }^{17}$ to reveal dislocations on all crystallographic faces of LiF. 
Several back-reflection Laue X-ray patterns were made from deformed crystals to determine a qualitative indication of the degree of polygonization. Specimens were exposed to tungsten $K_{\alpha}$ radiation at $50 \mathrm{kV}$ and $20 \mathrm{ma}$ for approximately 20 minutes. 
III. RESULTS

\section{A. Creep Curves}

Several representative creep curves are shown in Fig. 2 for I.R. crystals tested at $700^{\circ} \mathrm{C}$ in both $\langle 100\rangle$ and $\langle 111\rangle$ orientations. The principal feature to be noted is the extreme difference in length of primary creep periods for the two different stress axes. The <100> crystals cxhibited an extraordinarily long primary period; generally true strains as high as 0.20 or greater were required before steady-state creep was established. All crystals tested in the $\langle 100\rangle$ orientation exhibited this "exaggerated" primary creep behavior the length of which increased at the higher stresses and temperatures.

Crystals tested in the <1l]> orientation, on the other hand, exhibited short primary creep periods, as little as $0.02-0.05$ true strain being required for the establishment of steady-state conditions. Despite the large differences in primary creep periods, the final steady-state strain rates for crystals in the two orientations tested were normally within a factor of two of each other, <100> crystals usually having the higher rate for a given stress as shown in Fig. 2.

\section{B. 'Stress Dependence}

A first approximation of the relationship between the applied stress and the steady-state strain rate may be obtained by considering the experimental data in terms of the phenomenological relationships described previously in Eq. (3). Figure 3 is a plot of the steady-state creep rates as a function of applied stress for <100> crystals deformed at $650^{\circ}, 700^{\circ}$, and $750^{\circ} \mathrm{C}(0.8-0.9 \mathrm{Tm})$. The majority of the data is for I.R. quality material (open symbols) as this grade of material made 


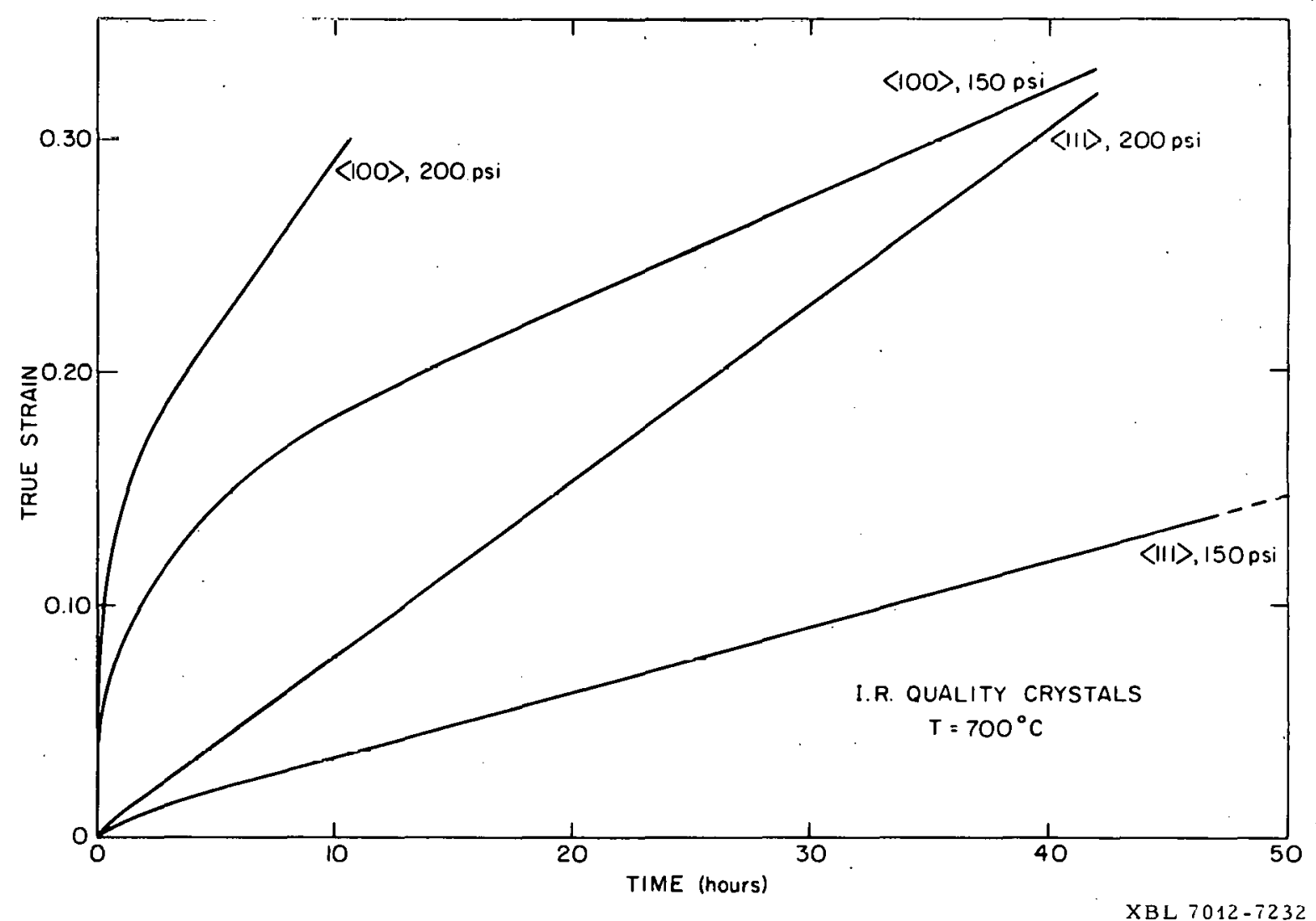

Figure 2. Representative creep curves for $\langle 100\rangle$ and $\langle 111\rangle$ crystals tested at $700^{\circ} \mathrm{C}$. 


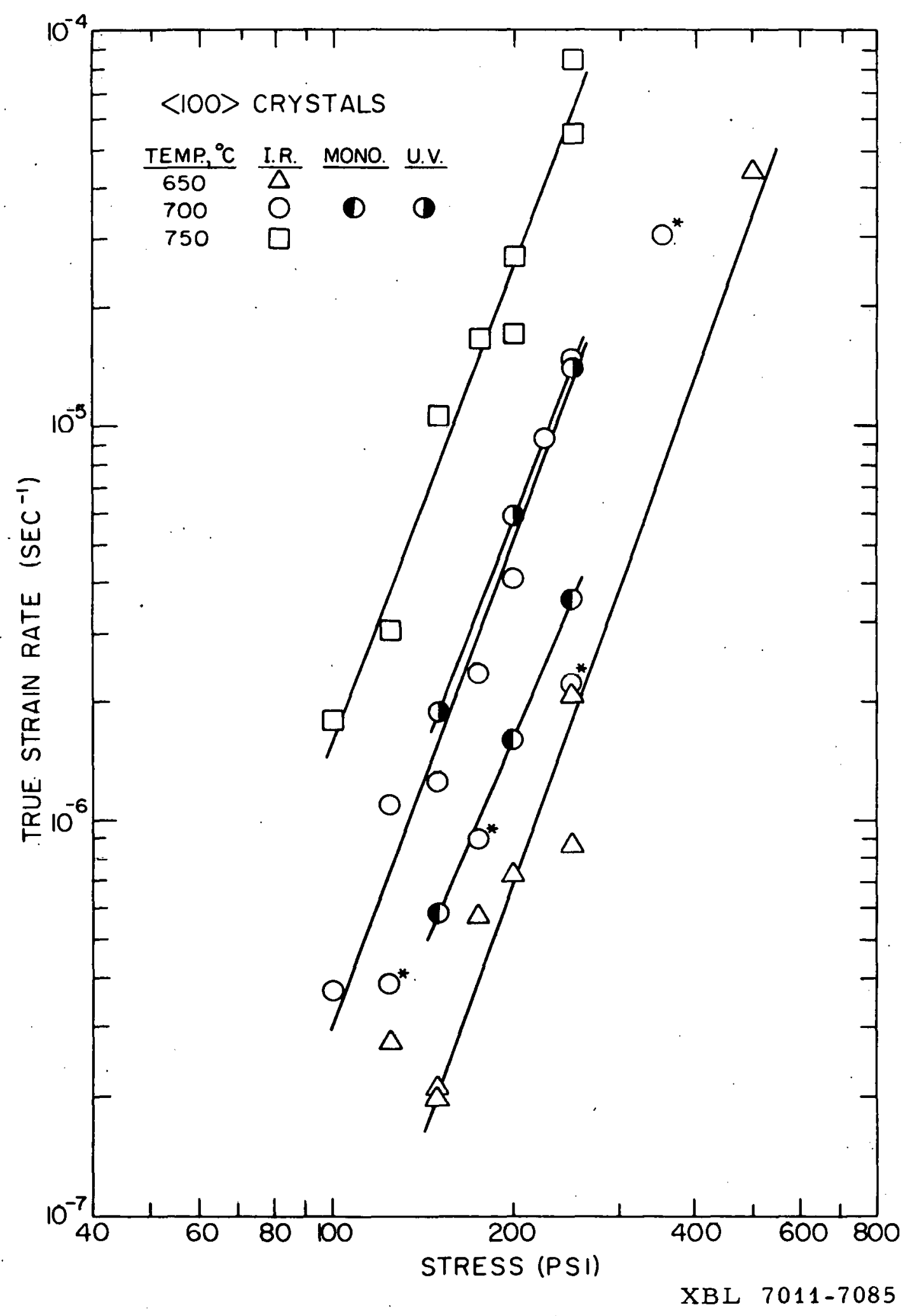

Figure 3. Strain rate vs. stress for $\langle 100\rangle$ crystals. 
up the bulk of the creep specimens. Data for Mono-quality and U.V. quality crystals are shown by half shaded symbols.

The results shown in Fig. 3 indicate that the relationship between steady-state strain rate and stress is in the form of a power law with the value of the stress exponent, corresponding to $\mathrm{n}$ in Eq. (3), equal to 3.9 for $650^{\circ}$ and $700^{\circ} \mathrm{C}$ and 4.0 for $750^{\circ} \mathrm{C}$ I.R. quality crystals. Slightly lower values of the stress exponent were obtained for Mono. $(n=3.6)$ and U.V. $(n=3.9)$ crystals at $700^{\circ} \mathrm{C}$ but since only three points each were obtained for these materials, the difference between them and the I.R. results is not considered to be significant.

Several < $100>$ crystals prepared in the form of cubes $(1 / t=1.0)$ were deformed at $700^{\circ} \mathrm{C}$ for comparison with crystals of the normal size $(1 / t=1.5-2.0)$. The results indicated by starred $(*)$ points in Fig. 3 were similar to the normal shaped specimens in that the stress exponent calculated from the four data points was equal to 4.1. The general con-. sequence of reducing the aspect-ratio of single crystal creep specimens appears to be a reduction in steady-state strain rate for a given stress without affecting the stress exponent. Langdon and Pask ${ }^{18}$ observed a similar reduction in strain rate with $1 / t$ for polycrystalline $\mathrm{MgO}$ creep experiments in compression while the stress exponent remained constant.

Figure 4 shows the stress-strain rate relationship for <lll> I.R. quality crystals tested at $700^{\circ} \mathrm{C}$. As for the $\langle 100\rangle$ crystals, a power law relationship is indicated with a calculated value of $n=3.4$. A comparison of the <lll> data with the data in Fig. 3 for <100> crystals at $700^{\circ} \mathrm{C}$ reveals rather close agreement between steady-state strain rates at corresponding stresses. This is particularly noteworthy in 


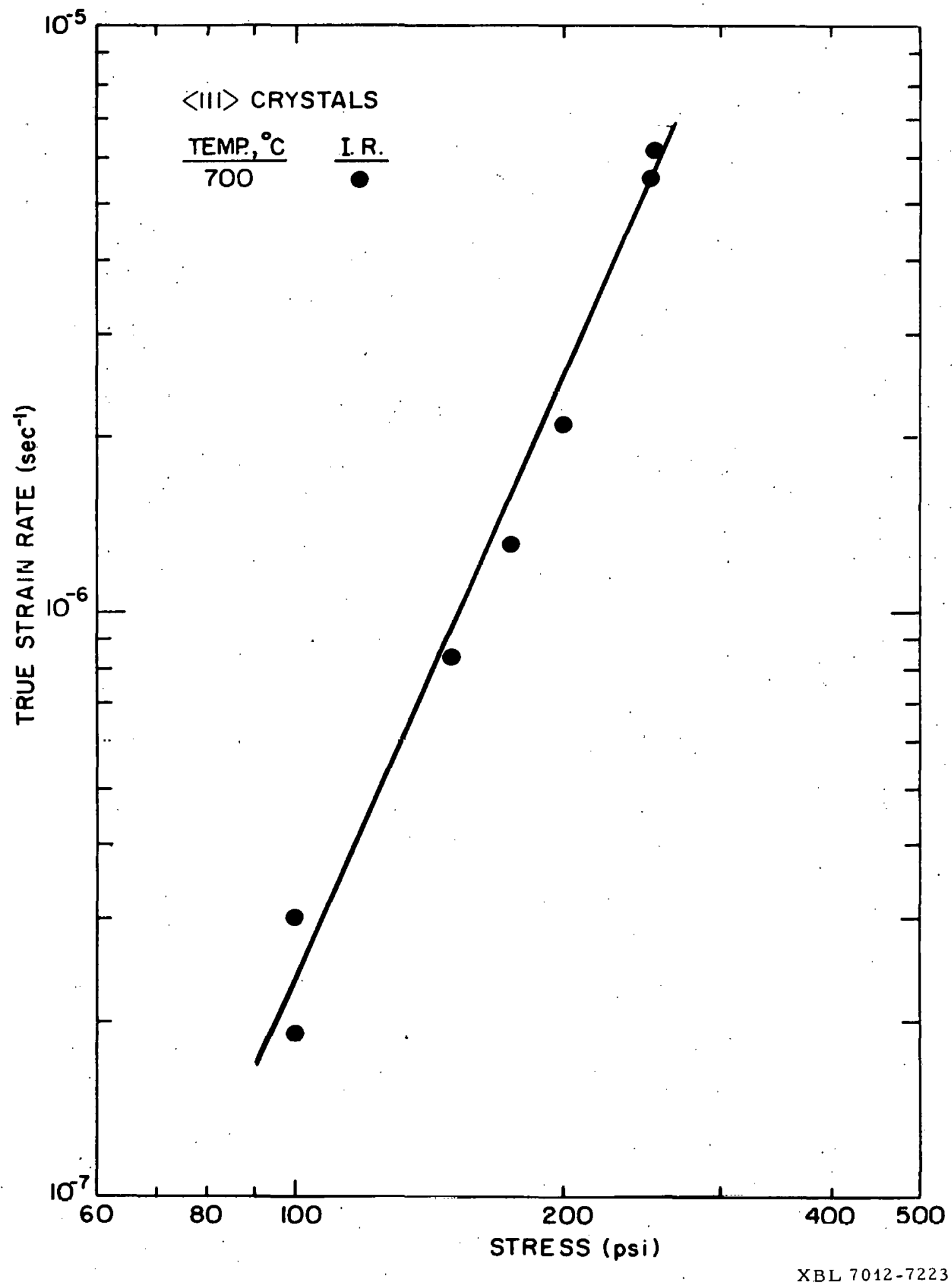

Figure 4. Strain rate vs. stress for $\langle l l l\rangle$ crystals. 
light of the marked contrast between the shape of the creep curves for the two orientations and the correspondingly much longer time for a <1ll> oriented crystal to reach an equivalent strain.

\section{Incremental Stress Tests}

Crystals tested in the <100> orientation gave inconsistent results when attempts were made to ascertain the stress dependence by the incremental technique. That true strains on the order of 0.20 were required before steady-state conditions were established particularly limited the usefulness of this approach for on changing the stress to higher values, new primary creep usually ensued requiring excessive total strains for the completion of the test. Also, strain rates were not reproducible on returning to a given stress after an intermediate stress change.

Contrasted to this unpredictable behavior, $\langle 11]\rangle$ crystals responded in an entirely consistent and reproducible manner to the incremental technique. For example, the results are shown in Fig. 5 for a <lll> crystal subjected to stresses between 100 psi and 250 psi during a single test sequence at $700^{\circ} \mathrm{C}$. The points plotted correspond to the ratios of stresses and steady state strain-rates after and before a given change of stress. The slope of the line shown results in a value of $n=3.3$ in excellent agreement with the $n=3.4$ value obtained for <lll>crystals in constant stress tests.

\section{Temperature Dependence}

To determine the apparent activation energy for creep, corresponding to $Q$ in $\mathrm{Eq}$. (3), values of $\ln \dot{\varepsilon}$ were plotted as a function of reciprocal absolute temperature for various constant stress levels. The results are shown in Figs. 6, 7 and 8 for <100> I.R. quality, <100> Mono. 


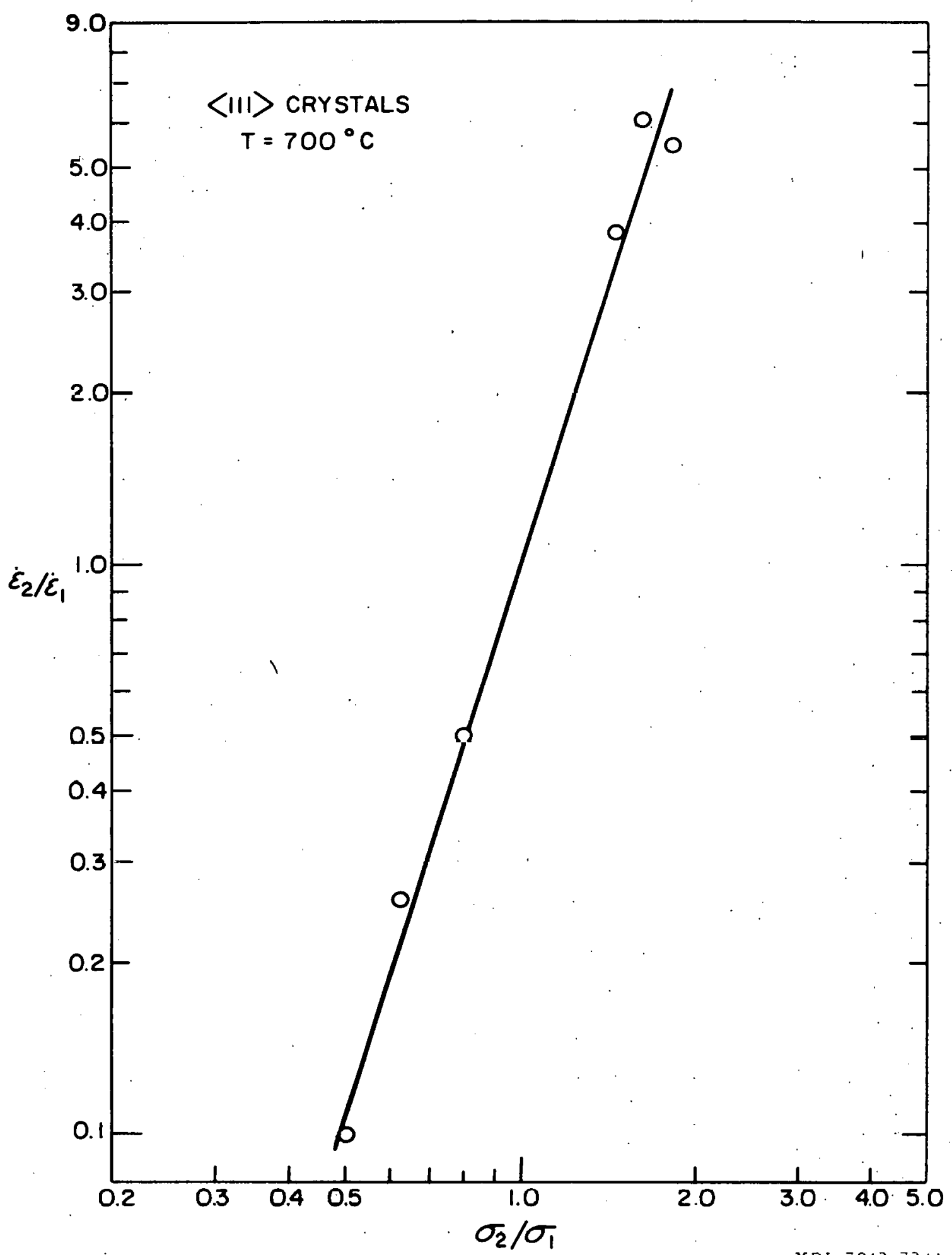

$X B L 7012-72 \angle 4$

Figure 5. Strain rate ratios vs. stress ratios from incremental stress test on a $\langle 111\rangle$ crystal. 


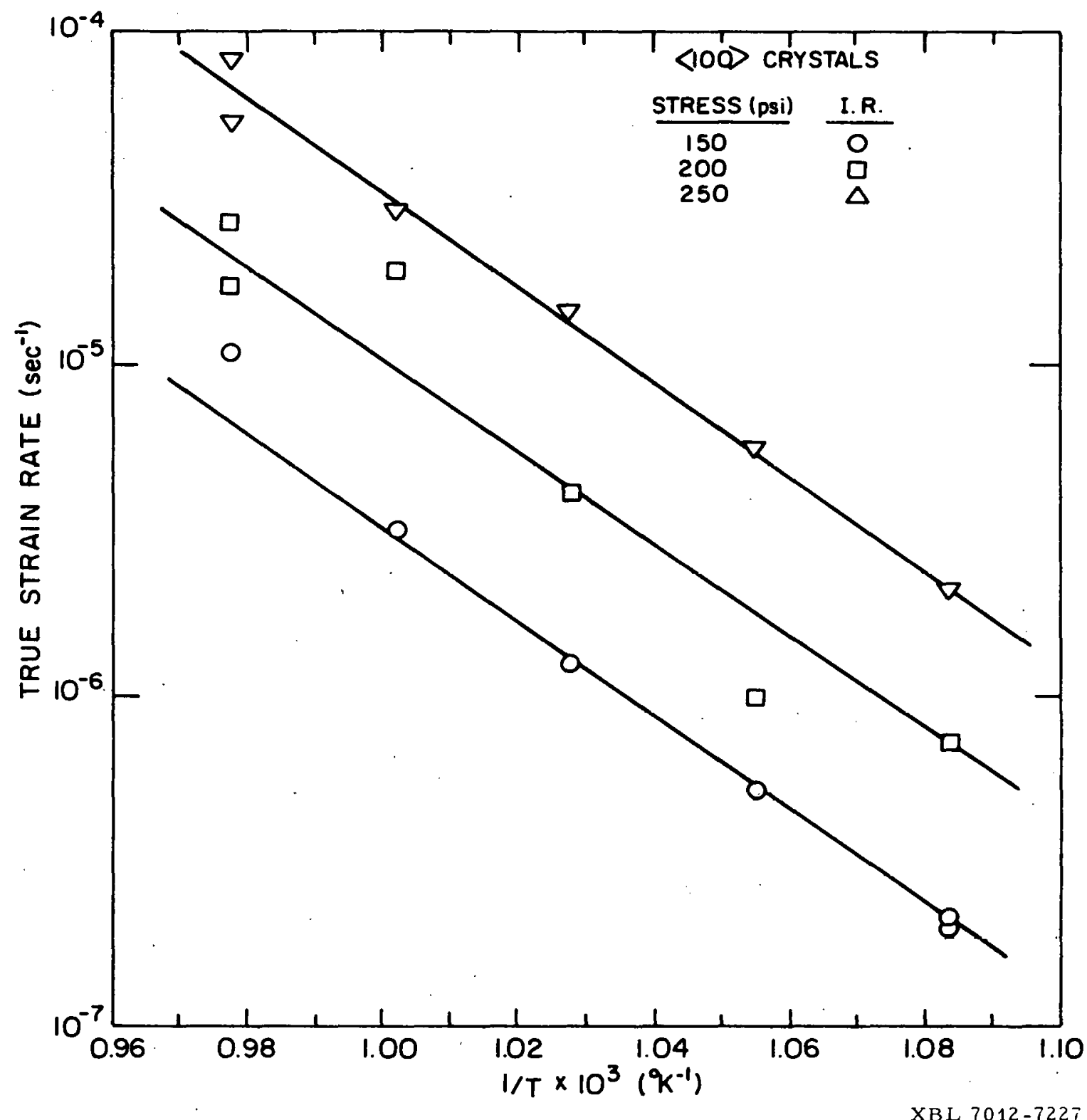

Figure 6. Strain rate vs. $1 / T$ for $\langle 100\rangle$, I.R. quality crystals. 


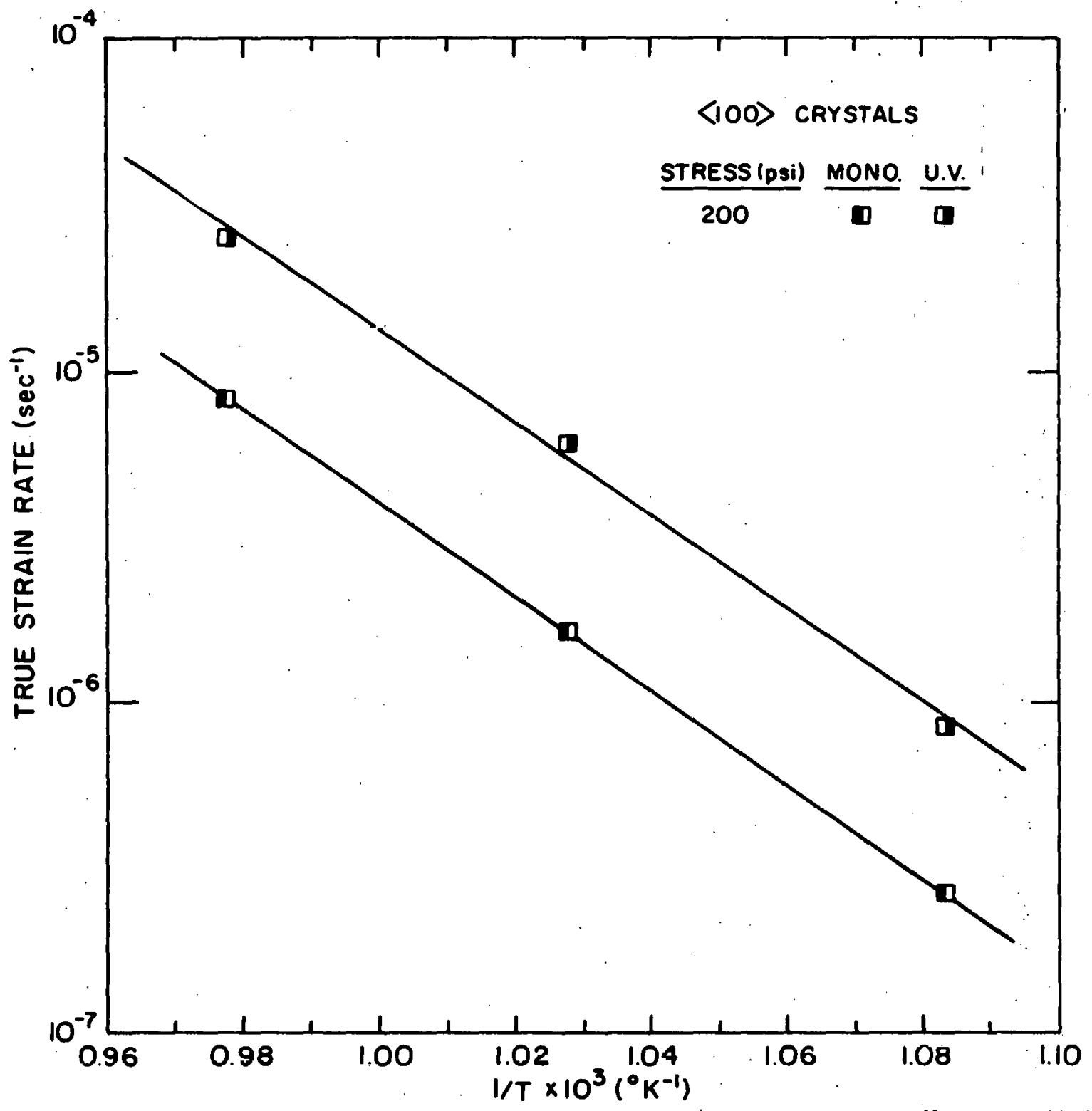

Figure 7. Strain rate vs. $1 / T$ for $\langle 100\rangle$, Mono. and U.V. quality crystals. 


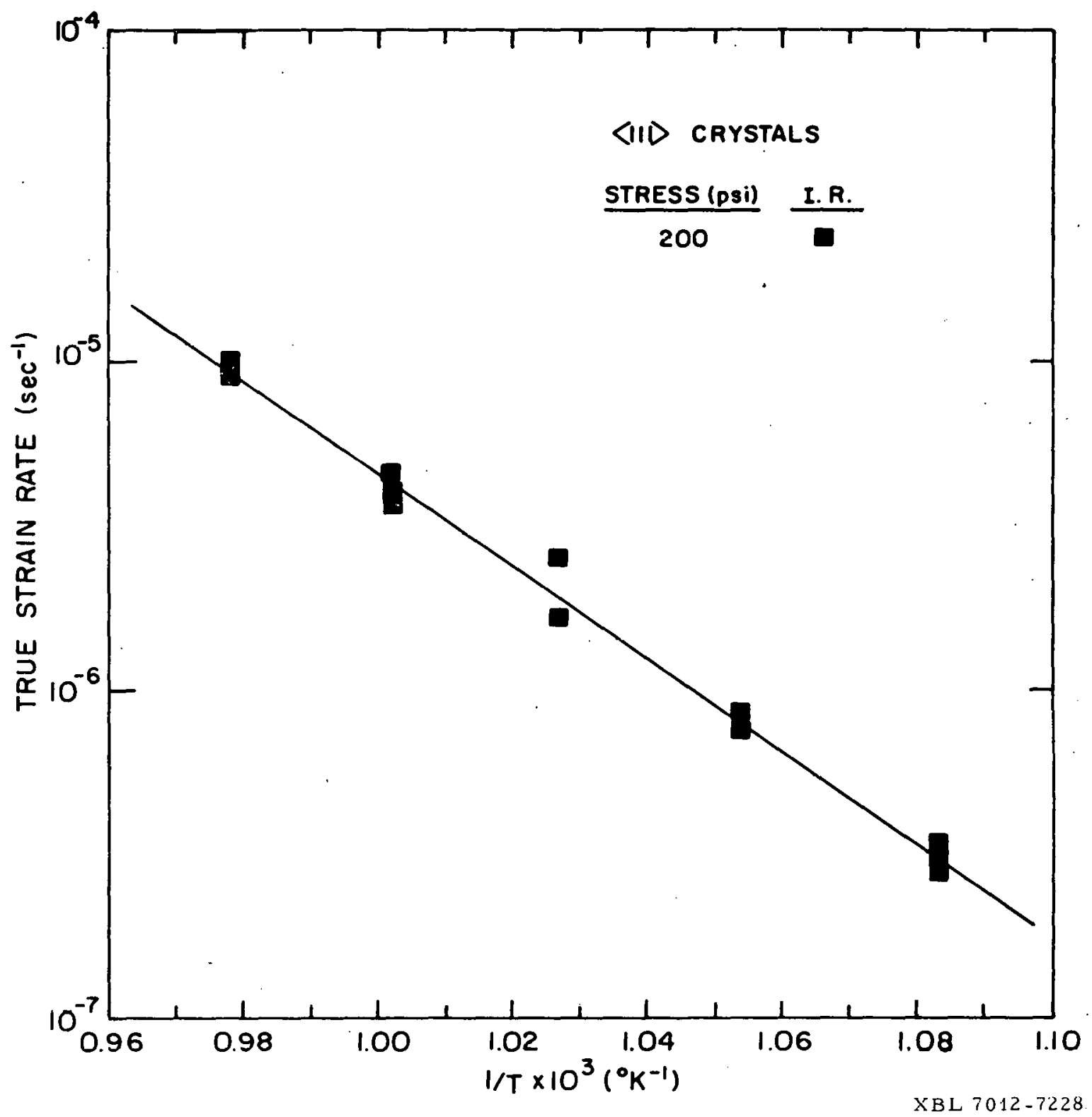

Figure 8. Strain rate vs. I/T for $\langle l l l\rangle$, I.R. quality crystals. 
and U.V. quality, and <IIl> I.R. quality crystals respectively. Values for $Q$ calculated from the slopes of the lines shown range from 64.1 to $65.6 \pm 7 \mathrm{kcal} / \mathrm{mole}$ suggesting that the apparent activation energy is independent of stress, purity and crystal orientation over the range of experimental conditions considered.

\section{E. Incrementil Temperature Tests}

Crystals tested in the $<1000$ orientation exhibited the same difficulties when subjected to incremental temperature tests as described previously for change in stress experiments. It was therefore impossible to determine a reliable value for $Q$ by this method.

In contrast, the results obtained from incremental tests for <lll crystals were, as for the incremental stress experiments, consistent and reproducible. The results are shown in Fig. 9 for a <lll> I.R. quality crystal cycled between $725^{\circ}$ and $750^{\circ} \mathrm{C}$ at a constant stress of 200 psi. Here, steady-state conditions were established quickly since the crystal responded rapidly to a change in temperature. The values of $Q$ calculated from each change, averaging $65.7 \mathrm{kcal} / \mathrm{mole}$, were closely grouped and in good agreement with the results from isothermal tests for <lll> crystals shown in Fig. 8, confirming the invariance of apparent activation energy with crystal orientation.

\section{F. Modulus of Elasticity}

The recent work of Mukherjee et $a l^{2}$ has shown how the apparent activation energy $Q$ obtained from direct experimental measurements may be in error due to the effect of the temperature variation of the shear modulus $G$ on the constarit lerm $A^{\prime}$ in E'q. (3). To determine this effect for the present work, Eq. (1) is rewritten in the form 


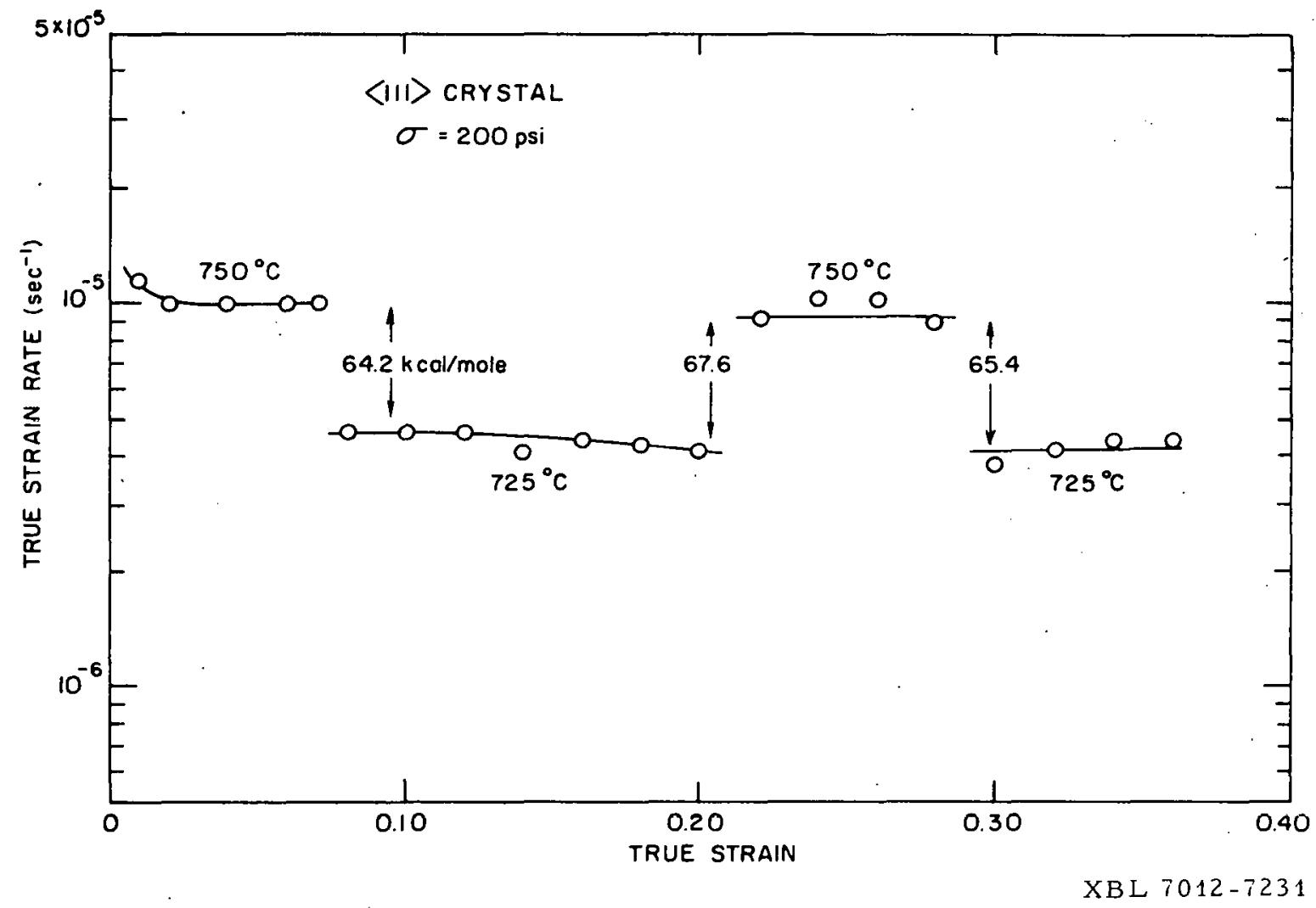

Figure 9. Strain rate vs. strain for <lll> crystal in incremental temperature test. 


$$
\dot{\varepsilon}=\frac{A^{\prime \prime} G}{T}\left(\frac{\sigma}{G}\right)^{n} e^{-Q} c^{/ R T}
$$

where $A^{\prime \prime}$ is a new constant incorporating those terms in $\mathrm{Eq}$. (1) which do not vary with temperature. This expression can be arranged in the form

$$
\frac{\dot{E} T}{G}=A^{\prime \prime}\left(\frac{\sigma}{G}\right)^{n} e^{-Q_{c} / R T}
$$

from which $Q_{c}$ may be obtained. Taking data at a constant value of $\frac{\sigma}{G}$ and two temperatures $T_{1}$ and $T_{2}$, the corrected value of activation energy is given by

$$
Q_{c}=\frac{R \ln \frac{(\dot{\varepsilon} T / G)_{2}}{\left(T_{2}-T_{1}\right) / T_{1} T_{2}}}{\left(T_{1}\right)_{1}}
$$

Shear modulus values for LiF single crystals obtained from the high temperature measurements of Hart $^{19}$ were used to calculate values of $\frac{\dot{\varepsilon} T}{G}$ and $\frac{\sigma}{G}$ which were then plotted for <100> crystals in Fig. 10. For constant values of $\frac{\sigma}{\mathrm{G}}$ between $7 \times 10^{-5}$ and $1.5 \times 10^{-4}$ the calculated values of $Q_{c}$ ranged from $51.0 \mathrm{kcal} / \mathrm{mole}$ to $55.2 \mathrm{kcal} / \mathrm{mole}$, about $10 \mathrm{kcal} / \mathrm{mole}$ less than the apparent activation energy values obtained from Fig. 6 . 


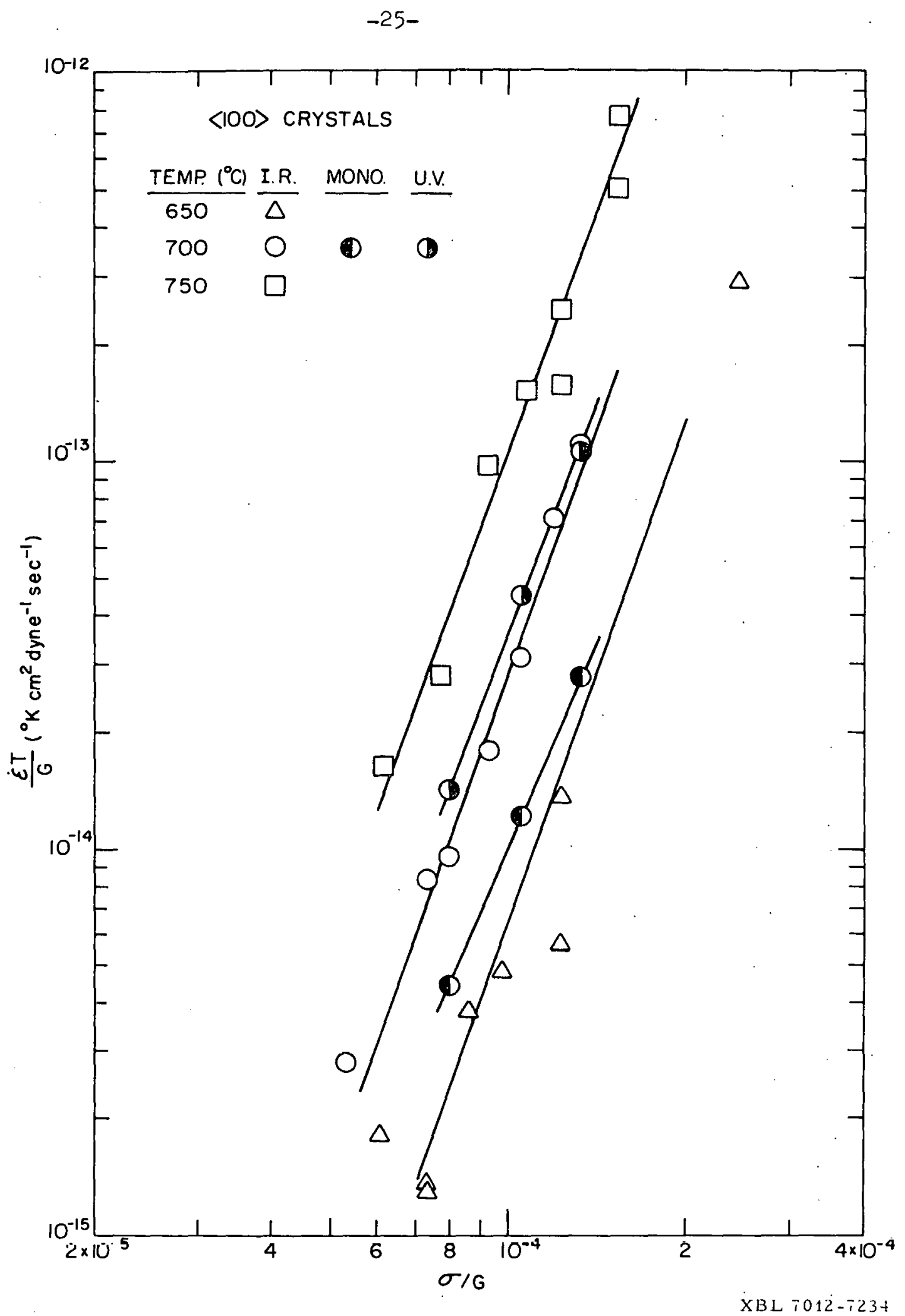

Figure 10. Normalized strain rate vs. normalized stress for $\langle 100\rangle$ crystals. 
IV. DISCUSSION

\section{A. Shape of Creep Curve}

The primary or decreasing strain rate portion of a creep curve. is usually associated with the development of a stable substructure characteristic of the experimental conditions. The marked contrast in length of primary creep period for $\langle 100\rangle$ and $\langle 1 l]\rangle$ oriented crystals, as shown in Fig. 2, probably reflects differences in the processes controlling the generation of substructure.

For crystals oriented with the applied stress parallel to $<100\rangle$, four $\{110\}\langle 1 \bar{I} 0\rangle$ slip systems are equally stressed. The studies of Copley and Pask ${ }^{20}$ and Day and Stokes ${ }^{2 l}$ on $\mathrm{MgO}$ and the more recent work of Day and Johnston ${ }^{22}$ on LiF have demonstrated the increasing resistance to dislocation intersections on orthogonal and oblique $\{110\}$ slip planes. For LiF crystals pulled in tension at initial strain rates of $28 \times 10^{-4}$ $\sec ^{-1}$, Day and Johnston ${ }^{2 \varepsilon}$ have shown that even at $700^{\circ} \mathrm{C}\left(0.87 \mathrm{~T}_{\mathrm{m}}\right)$ interpenetration of slip on orthogonal systems did not occur freely and that oblique slip was even more difficult. Orthogonal intersections should result in formation of jogs as the two intersecting dislocations cannot lower their cnergy by combining to form a third dislocation. Dislocations intersecting on oblique $\{110\}$ planes can react to form a third sessile dislocation lying parallel to <lll>. Arrays of these pure edge sessile dislocations are thought to rearrange themselves by climb processes at temperatures above $0.5 \mathrm{~T}_{\mathrm{m}}$. That true strains in excess of 0.20 are required for the establishment of steady state creep in <100> crystals may reflect the continuing resistance to intersection arid subsequent rearrangement of dislocations moving on oblique $\{110\}$ planes. 
In contrast to the behavior of $\langle 100\rangle$ crystals, dislocations moving on the three equally stressed $\{100\}$ glide planes for crystals in the $\langle 111\rangle$ orientation do not react upon intersection. This may be reflected in the relatively short primary period observed for $\langle l l l\rangle$ crystals as steadystate conditions are established within a few minutes of the application of the stress.

Stress-strain curves obtained in the course of this study on crystals of both orientations correlate well with the observed creep behavior. Figure 11 shows stress-strain curves in compression at $700^{\circ} \mathrm{C}$ for both orientations. The initial strain rate, $27.5 \times 10^{-5} \mathrm{sec}^{-1}$, was chosen to correspond with the steady-state creep rates observed in the creep tests. After yielding and a limited "easy-glide" region, the <100> crystal strain hardens at an increasing rate up to the end of the test at a true-strain of 20.35 , corresponding to the increasing difficulty of slip. In contrast, though the yield stress is considerably higher for the <ll1> crystal, once deformation begins, it continues with essentially no strain hardening; this portion of the stress-strain curve corresponds essentially to steady-state creep at a stress of approximately 900 psi.

An additional factor which may tend to differentiate between the two orientations is the relationship of the observed yield stresses in the stress-strain curves to the range of creep stresses employed. For both $\langle 100\rangle$ and $\langle l l l\rangle$ crystals, creep stresses ranged from 100 psi to a maximum of 250 psi. Thus for <lll> crystals the creep stresses would normally be considerably less than that required for macroscopic yielding, while for $\langle 100\rangle$ crystals creep stresses generally exceeded the 


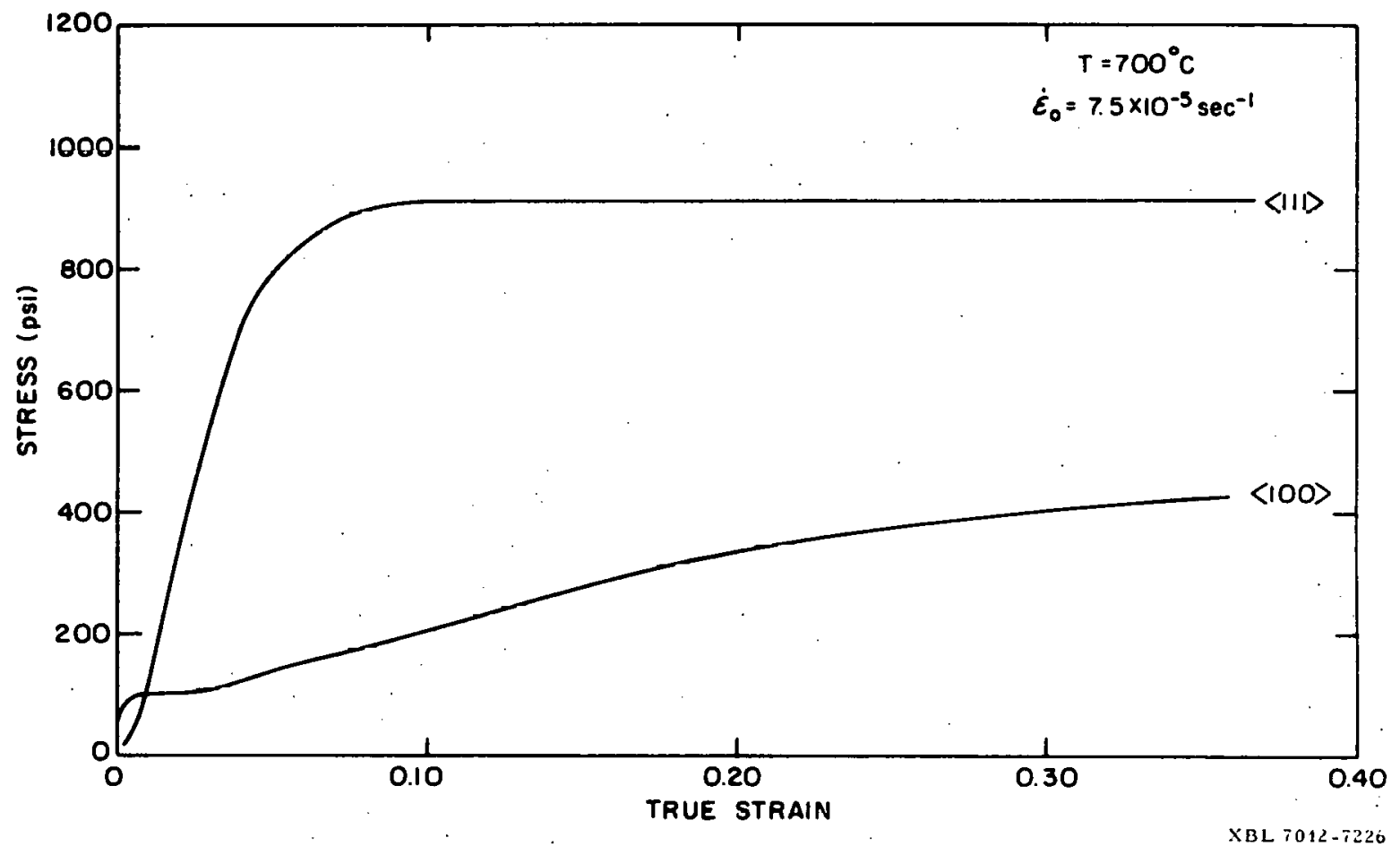

Fi gure 1i. Compressive stress-strain curves for $\langle 100\rangle$ and $\langle 111\rangle$ crystals. 
yield stress. Thus the relatively greater amount of plastic deformation introduced by application of the creep stress for $\langle 100\rangle$ crystals may result in a correspondingly longer period of primary creep before the equilibrium substructure required for steady-state creep can be established.

It should be noted that this particular trend in stress-strain behavior is the reverse of that observed previously for MgO by Copley and Pask. ${ }^{20}$ The strain hardening rate for $\langle l l l\rangle$ oriented MgO crystals in compression was there found to be considerably greater than that for $<100>$ crystals for all temperatures up to $1600^{\circ} \mathrm{C}\left(\mathrm{i} .61 \mathrm{~T}_{\mathrm{m}}\right)$, the limit of test temperatures employed in that investigation.

\section{B. Stress Dependence}

The value of the stress exponent, $\mathrm{n}$, in $\mathrm{Eq}$. (3) may be used as an indication of the particular rate controlling mechanism for creep. For polycrystalline materials under conditions where creep occurs without the motion or interaction of dislocations, so-called "viscous" or diffusional creep, a stress exponent of $I$ is often found as predicted by the theories of Nabarro, ${ }^{23}$ Herring $^{24}$ and Coble. 25 Creep models involving the motion of dislocations either by glide or climb predict higher values of $\mathrm{n}$. In a recent review of dislocation models of creep, Weertman ${ }^{26}$ has shown how $n$ may be found to vary from 3 to 6 or even higher, depending on the particular dislocation mechanism predominating. Over the limited range of stresses and temperatures employed in this investigation, experimental values of $n$ range from 3.6 to 4.1 for <100> oriented crystals of all purities, and equal 3.4 for <lll> oriented I.R. quality crystals. The observed values of $n$ thus fall 
within the range anticipated for a rate controlling mechanism involving climb or other non-conservative motion of dislocations.

The various theoretical models of creep deformation were recently reviewed by Mukherfee, Bird and Dom ${ }^{1}$ who concluded that for metals exhibiting a stress exponent in the range from 3 to 6 , the climb of edge dislocations is the most probable rate controlling mechanism for creep. The dislocation climb theories of Weertmann, ${ }^{27} \mathrm{Chang}^{28}$ and Nabarro 29 each predict a power-1 aw stress dependence with $\mathrm{n}=4.5,4.0$ and 3.0 respectively, all in agreement with the range of experimentally observed values. Gifkins ${ }^{30}$ has pointed out the dangers in attempting to unambiguously identify creep mechanisms from measurements made over limited ranges of the experimental variables. Therefore, on the basis of relative agreement of the measured and anticipated values of $n$, a dislocation climb mechanism of some type is thought to control the high temperature creep behavior of LiF single crystals.

\section{Temperature Dependence}

The activation energies for creep deformation in many materials have been shown to agree well with activation energies for self diffusion. For pure metals with but one atomic species the agreement is particularly good while in non-metallic systems there are not yet sufficiently numerous or precise measurements to reach the same conclusion with complete certainty.

Table II summarizes the activation energies for diffusion in lithium fluoride obtained from NMR measurements by Eisenstadt ${ }^{31}$ and Stoebe and Huggins, ${ }^{32}$ and from the conductivity data of Haven. ${ }^{33}$ Experimental values of $Q$ from isothermal tests for $\langle 100\rangle$ and $\langle 111\rangle$ 
Table II. Activation Energies for Dissuion in LiF

\begin{tabular}{|c|c|c|c|c|}
\hline \multicolumn{2}{|c|}{ Extrinsic } & \multicolumn{2}{|c|}{ Intrinsic } & \multirow[b]{2}{*}{ Reference } \\
\hline${ }_{D}^{Q}\left(\mathrm{Li}^{+}\right)$ & $\mathrm{Q}_{D}\left(\mathrm{~F}^{-}\right)$ & $Q_{D}\left(\mathrm{Li}^{+}\right)$ & $Q_{D}\left(F^{-}\right)$ & \\
\hline $16.3 \mathrm{kcal} / \mathrm{mole}$ & - & $41.7 \mathrm{kcal} / \mathrm{mole}$ & $50.7 \mathrm{kcal} / \mathrm{mole}$ & 31 \\
\hline 15.2 & - & 43.0 & - & 32 \\
\hline 14.9 & - & 45.7 & - & 33 \\
\hline
\end{tabular}

crystals (Figs. 6,7 and 8), averaging $65 \mathrm{kcal} / \mathrm{mole}$, are somewhat in excess of any of the previously reported values for diffusion in lithium fluoride. However, when the creep equation is correctly formulated to include the effect of temperature variation of the shear modulus as described in Section III-F, the calculated values of $Q_{c}, 51-55 \mathrm{kcal} / \mathrm{mole}$, fall in good agreement with Eisenstadt's ${ }^{31}$ value for fluorine ion diffusion. This figure also agrees with the results of Cropper and Langdon ${ }^{13}$ for polycrystalline LiF in which the activation energy for creep was determined to be $50.1 \mathrm{kcal} / \mathrm{mole}$. Thus, as in the case for many metallic systems, it appears that the high temperature creep deformation of LiF single crystals is controlled by lattice diffusion with the ratecontrolling species being the larger, slower moving fluorine ion. D. Mechanism and Correlation with Other Systems

In order to further check the applicability of Eq. (5) to the present system, and to determine the stress exponent $\mathrm{n}$ in the revised. formulation, a plot of $\frac{\dot{\varepsilon} T}{G} e^{Q} c^{/ R T}$ vs $\frac{\sigma}{G}$ was prepared taking an average value for the corrected activation energy $Q_{c}=53 \mathrm{kcal} / \mathrm{mole}$. In Fig. 12 the data for crystals of both orientations and all purities are shown 


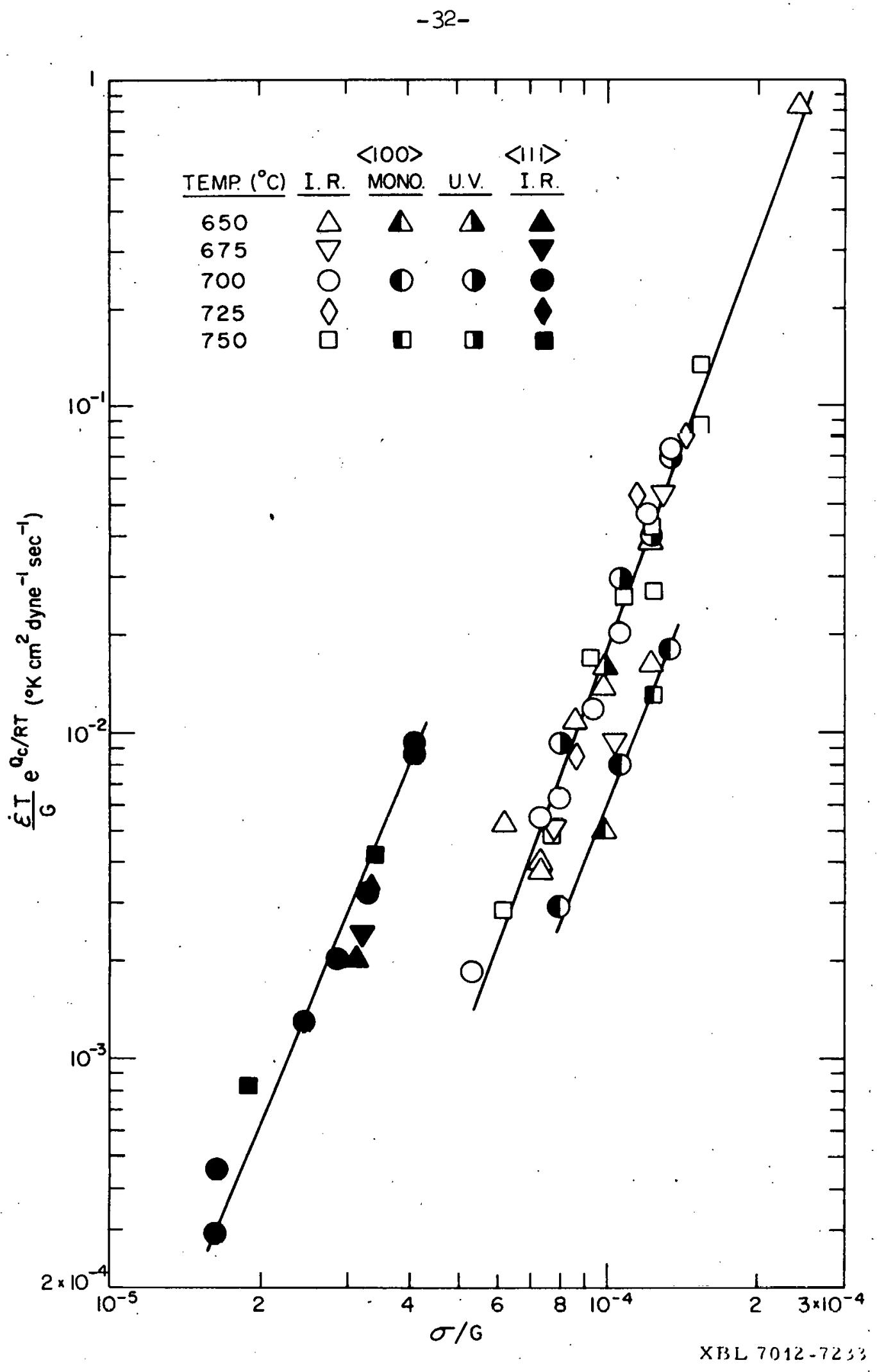

Figure 12. Temperature compensated strain rate vs. normalized stress for all crystals. 
together. Data points for the I.R. quality material over the complete range of temperatures and stresses (unshaded symbols) are reduced to a single straight line relationship whose slope, corresponding to $\mathrm{n}$ in Eq. (5) is equal to 4.0. The Vac. U.V. quality points are virtually superimposed on the pattern of the I.R. data while the lower purity, Mono. quality data falls slightly below. Thus the additional cation impurity level in the Mono. quality material appears to reduce the effective strain rate for a given value of $\frac{\sigma}{G}$ while not appreciably altering the value of $n$. In a similar manner, the effect of specimen orientation on the observed creep behavior seems to be a displacement of the data along both the rate and stress axes while not significantly affecting the relationship between strain rate and stress. The shift is principally the result of higher values of the shear modulus $G$ for crystals stressed in the <lll> orientation which reduces the calculated $\frac{\sigma}{G}$ and $\frac{\dot{\varepsilon} T}{G} e^{Q} c / R T$. In the case of <lll> oriented crystals, as was found for crystals of different purities, the basic power law relationship between strain rate and stress does not appear to be affected. The value of $n$ calculated from the <lll> data of Fig. 12 gives the result $\mathrm{n}=3.2$, slightly less than that found for <100> crystals but still within the range anticipated for a dislocation climb controlled mechanism.

Finally, following the analysis presented by Mukherjee et al. ${ }^{2}$ it would be of interest to replot the data obtained here in a form which would allow comparison with creep studies in metallic systems. For this purpose, Eq. (1) is rewritten 


$$
\frac{\dot{\varepsilon} k T}{D G b}=A\left(\frac{\sigma}{G}\right)^{n}
$$

where $\mathrm{D}$ is taken to be the diffusivity of the rate controlling species in a non-metallic material. Using $D$ values obtained from the results of Eisenstadt ${ }^{31}$ for $\mathrm{F}^{-}$ion diffusion in LiF, and taking $\mathrm{b}=2.83 \times 10^{-8} \mathrm{~cm}$ the resulting plot is shown in Fig. 13. The same general trends as obtained in Fig. 12 are observed here. The <100> I.R. quality material at all temperatures and stresses results follow a power law with $n=4.1$; the results are thus best represented by the relationship

$$
\frac{\dot{\varepsilon} \mathrm{kT}}{\mathrm{DGb}}=8.9 \times 10^{3}\left(\frac{\sigma}{G}\right)^{4.1}
$$

where $D$ is the diffusivity of the fluorine ion. The other purities and <ll]> data give slightly different values of $n$ ranging from 3.1 for <IIl> crystals to 3.9 for the U.V. qual. <I00> crystals. Thus, as for the previous case the values of $n$ agree well with results obtained in metallic systems when creep is controlled by dislocation climb. When plotted in terms of the dimensionless parameters $\frac{\dot{\varepsilon}_{\mathrm{kT}}}{\mathrm{DGb}}$ and $\frac{G}{G}$ as shown in Fig. 13, the results for single crystal LiF agree well with the general findings of Mukherjee et al. ${ }^{2}$ for f.c.c. metals which is represented by the area between the two dashed lines. The results for <100> crystals fall within the range of metallic systems while the <lll> results fall slightly outside the regime representative of f.c.c. metals. In addition, the results obtained previously by Cropper and Langdon ${ }^{13}$ 


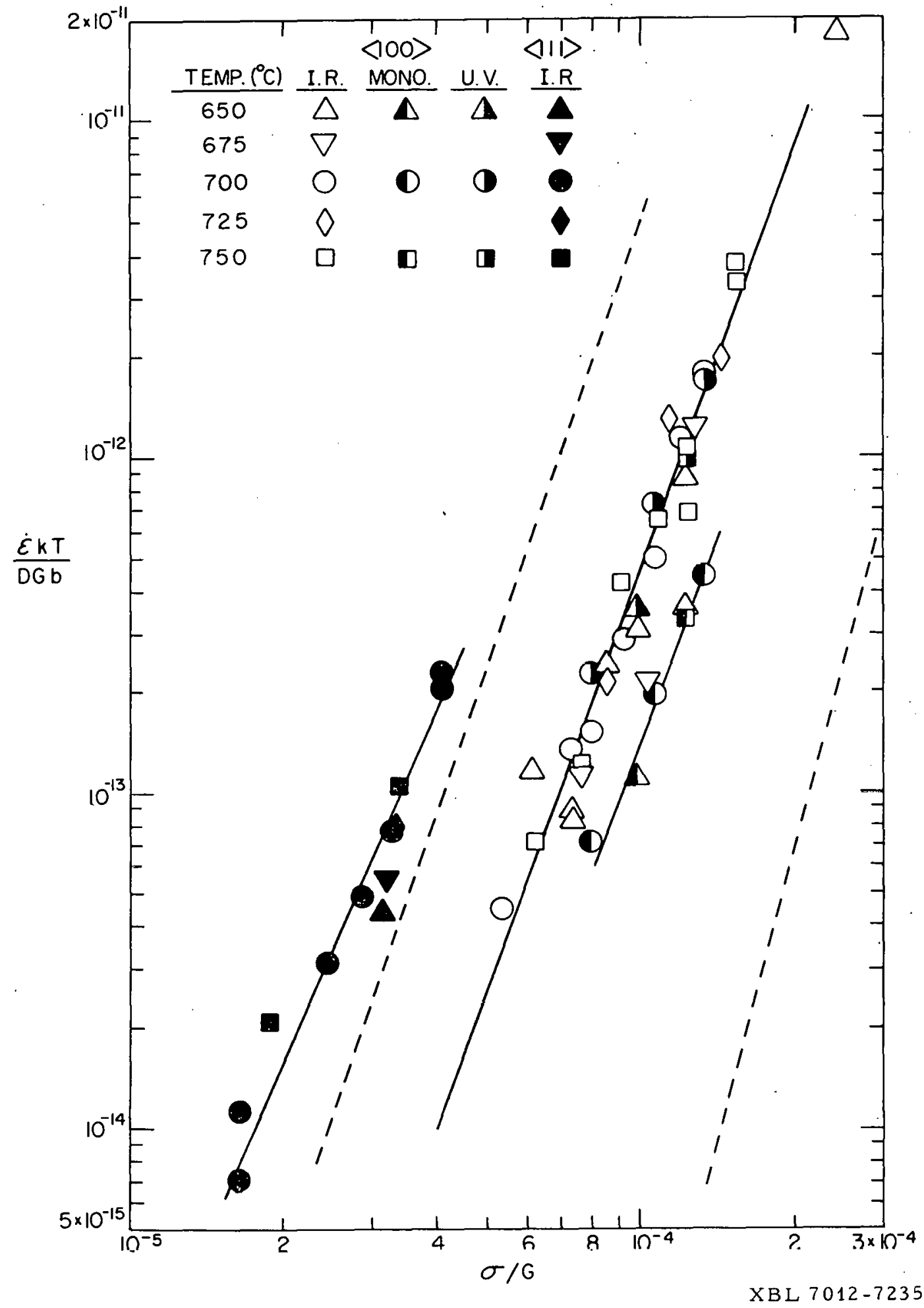

Figure 13. Dimensionless strain rate function vs. normalized stress for all crystals. 
for polycrystalline LiF, when plotted in terms of the dimensionless parameters of Eq. (7) very nearly coincide with the <l00> oriented single crystal results. The stress exponent found in that study was considerably higher than that observed here $(n=6.6$ vs $n=4.1)$, and may reflect the additional constraint imposed on the deformation process by the presence of grain boundaries. Nevertheless, the agreement between results for single crystal and polycrystalline LiF with the general trends observed in f.c.c. metals. leads to the general conclusion that similar mechanisms, probably involving the climb of dislocations, control the high temperature creep behavior of these materials.

\section{E. Microstructure}

Back reflection Laue $\mathrm{X}$-ray photographs of $\langle 100\rangle$ oriented crystals deformed at $700^{\circ} \mathrm{C}$ and $750^{\circ} \mathrm{C}$ and a st.ress of $13 n$ psi. are show in Figc. 14 and 15 for comparison with an undeformed crystal shown in Fig. 16. All crystals were oriented such that the incident X-ray beam was parallel to a cube axis. Extensive subgrain formation is indicated by the replacement of each of the single spots in the pattern of the undeformed crystal with an array of spots each diffracted from a different slightly misorlented subgrain in the deformed crystals. On the basis of the Laue patterns, the degree of misorientation between subgrains is estimated to be not more than about five degrees.

Optical microscopy confirmed the formation of subgrains which were revealed by sectioning the deformed crystals parallel to the stress exis, chemically polishing and etching the surface. Photomicrographs of four $\langle 100\rangle$ crystals deformed at $700^{\circ} \mathrm{C}$ and stresses of $100,150,200$ andi 250 psi are shown in Figs. 17-20, respectively. In these and all 


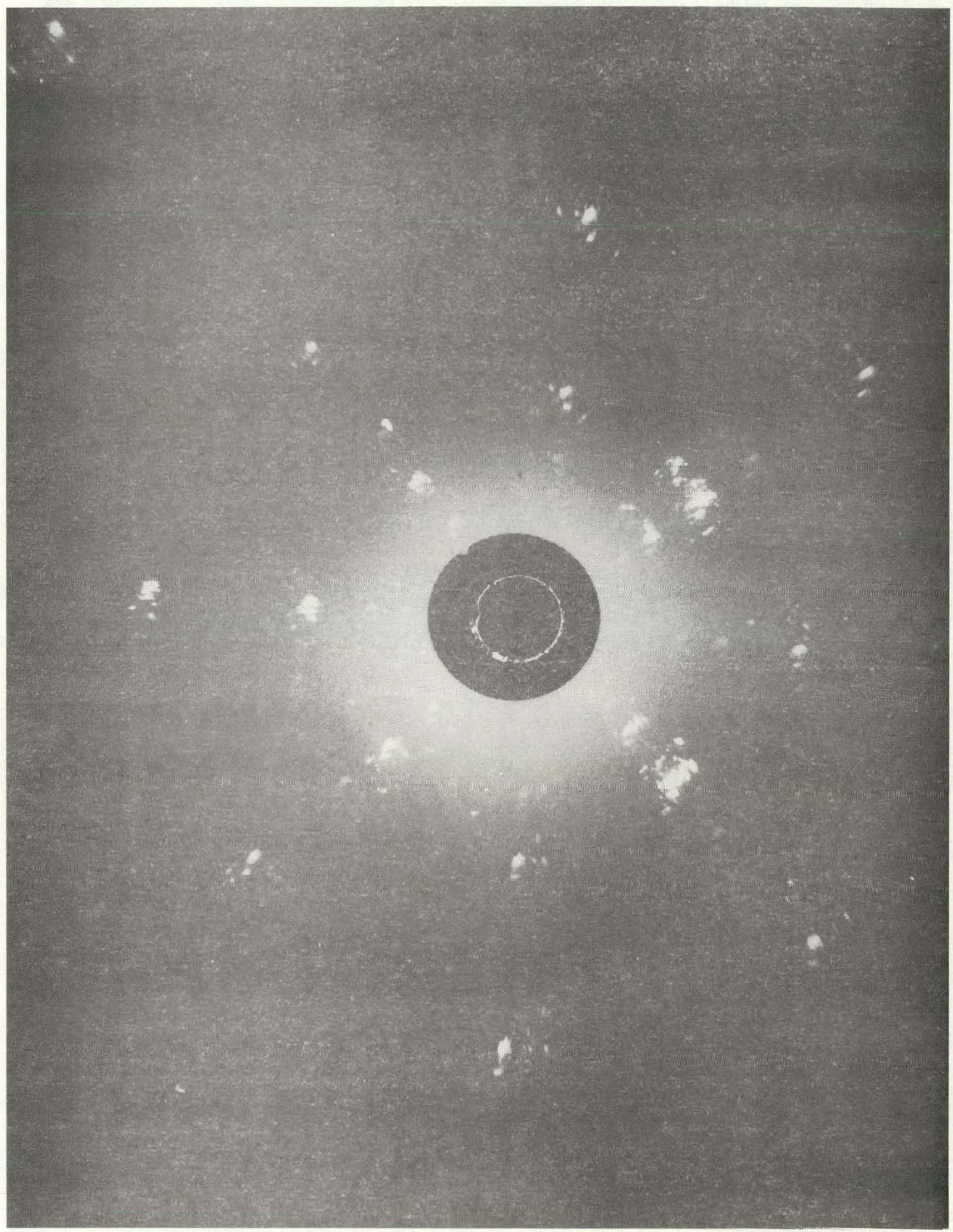

XBB7012-5389

Figure 14. Laue pattern of $\langle 100\rangle$ crystal deformed at $700^{\circ} \mathrm{C}$. 
$-38-$

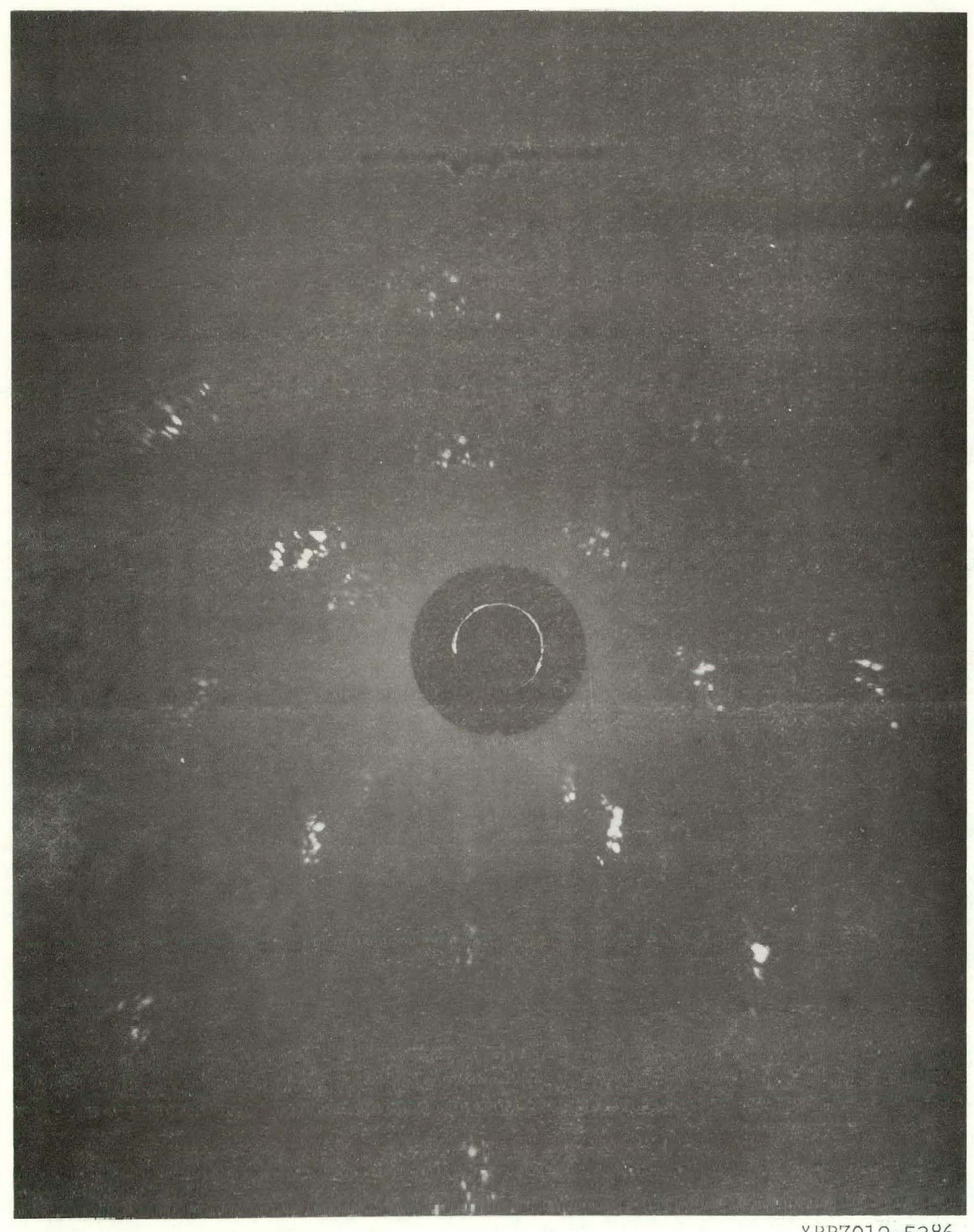

XBB7012-5386

Figure 15, Laue pattern of $\langle 100\rangle$ crystal deformed at $750^{\circ} \mathrm{C}$. 


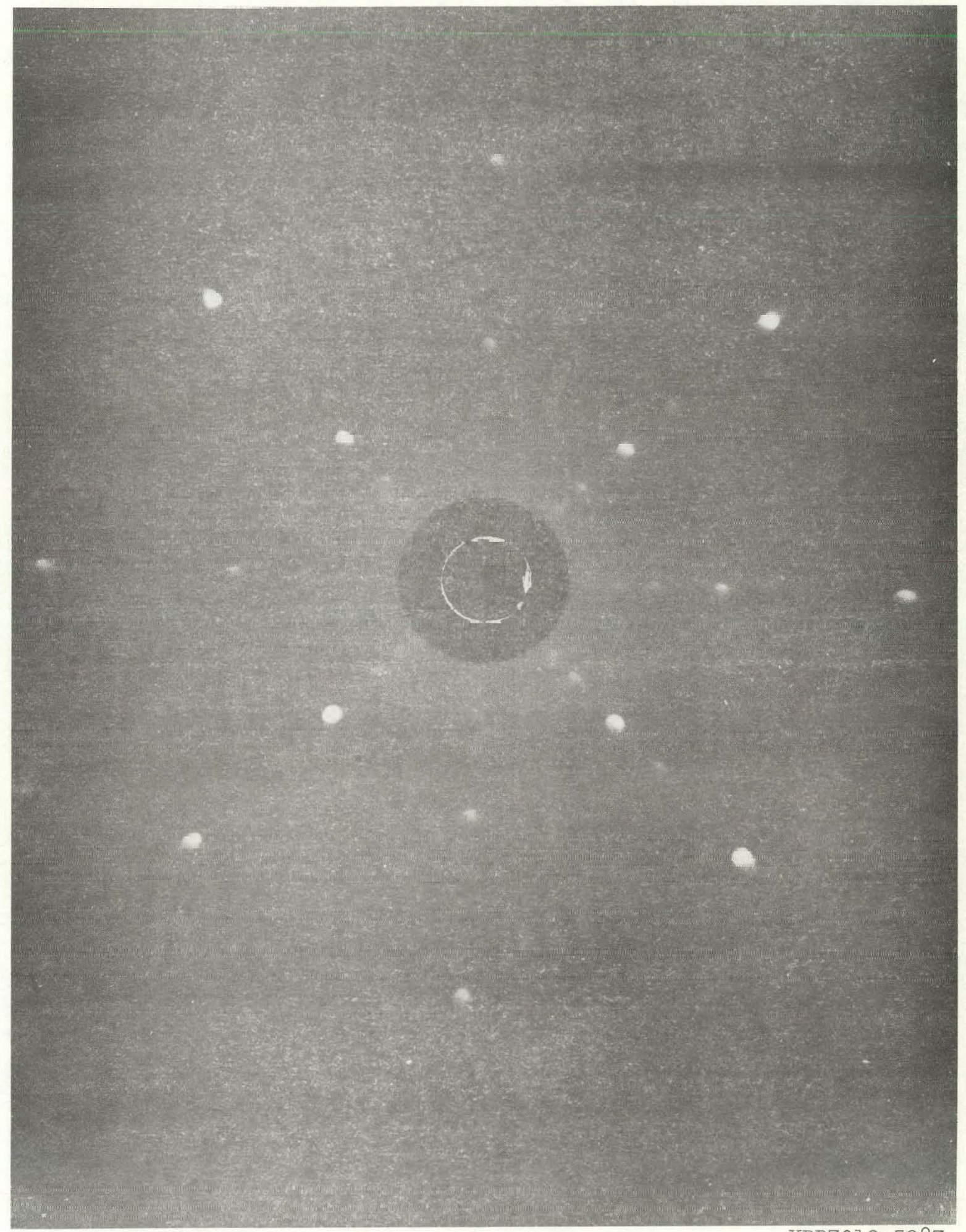

Figure 16. Laue pattern of undeformed <100> crystal. 


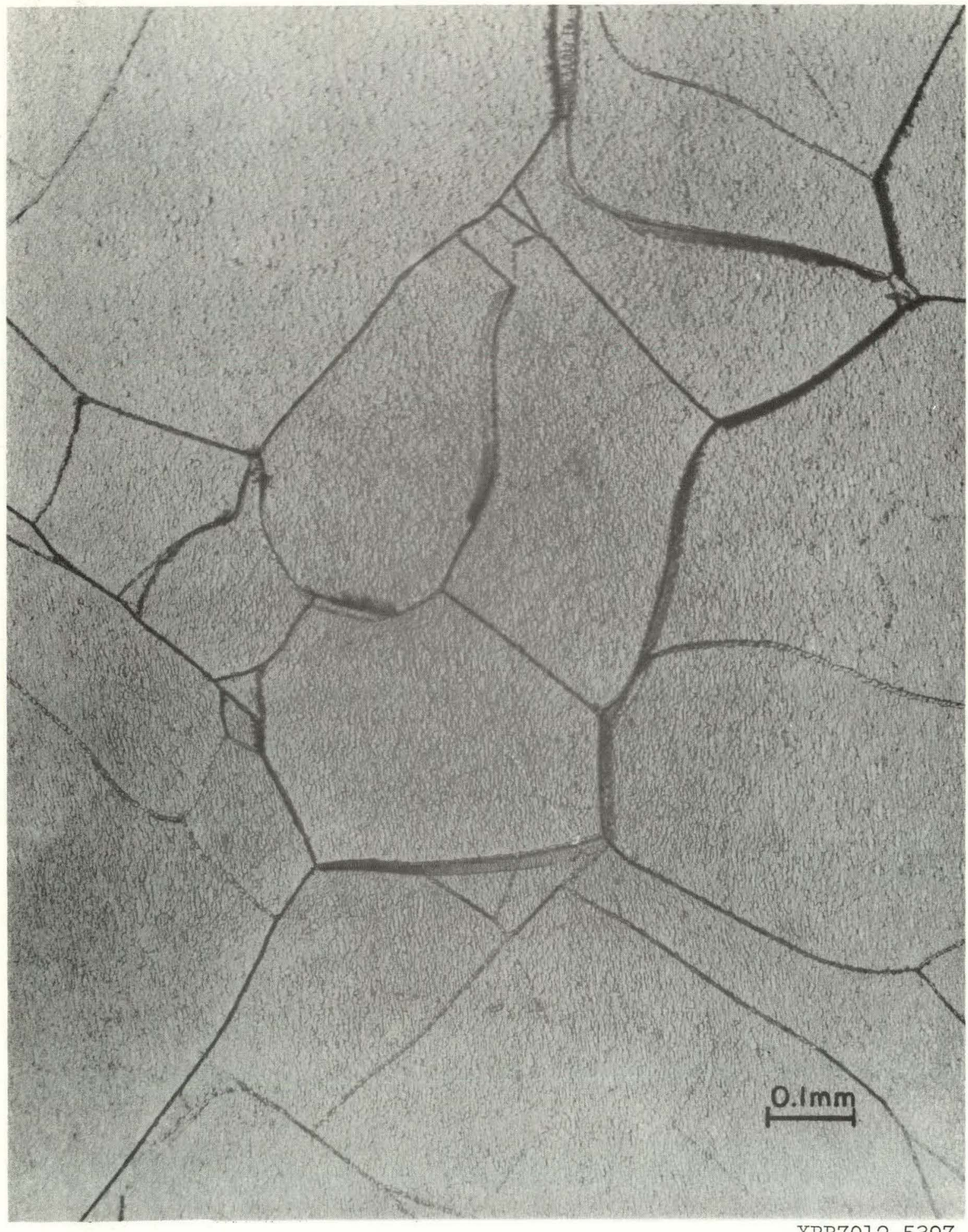

XBB7012-5397

Figure 17. <100> crystal deformed at $700^{\circ} \mathrm{C}$ and $100 \mathrm{psi}$. 


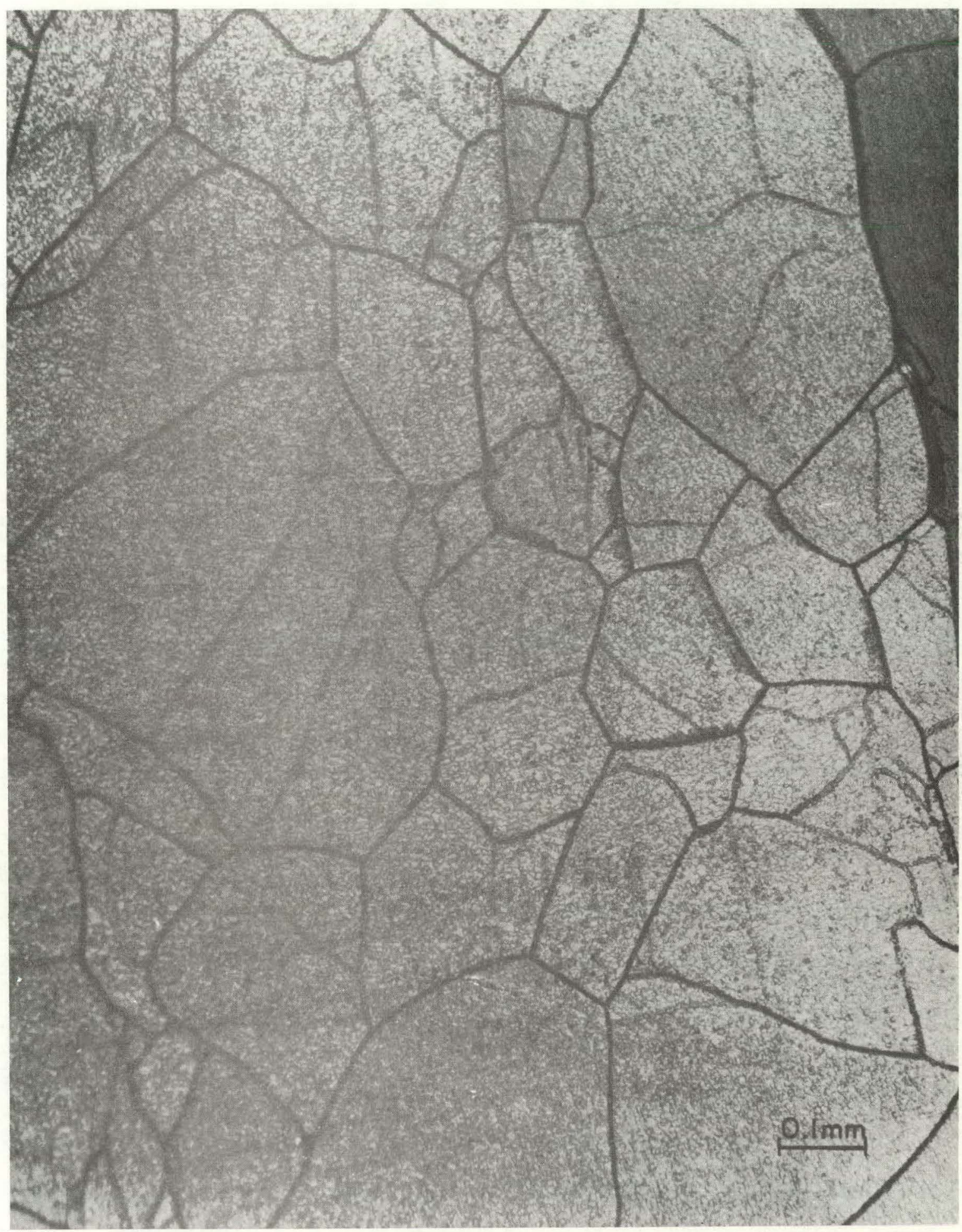

XBB7012-5399

Figure 18. <l00> crystal deformed at $700^{\circ} \mathrm{C}$ and 150 psi. 


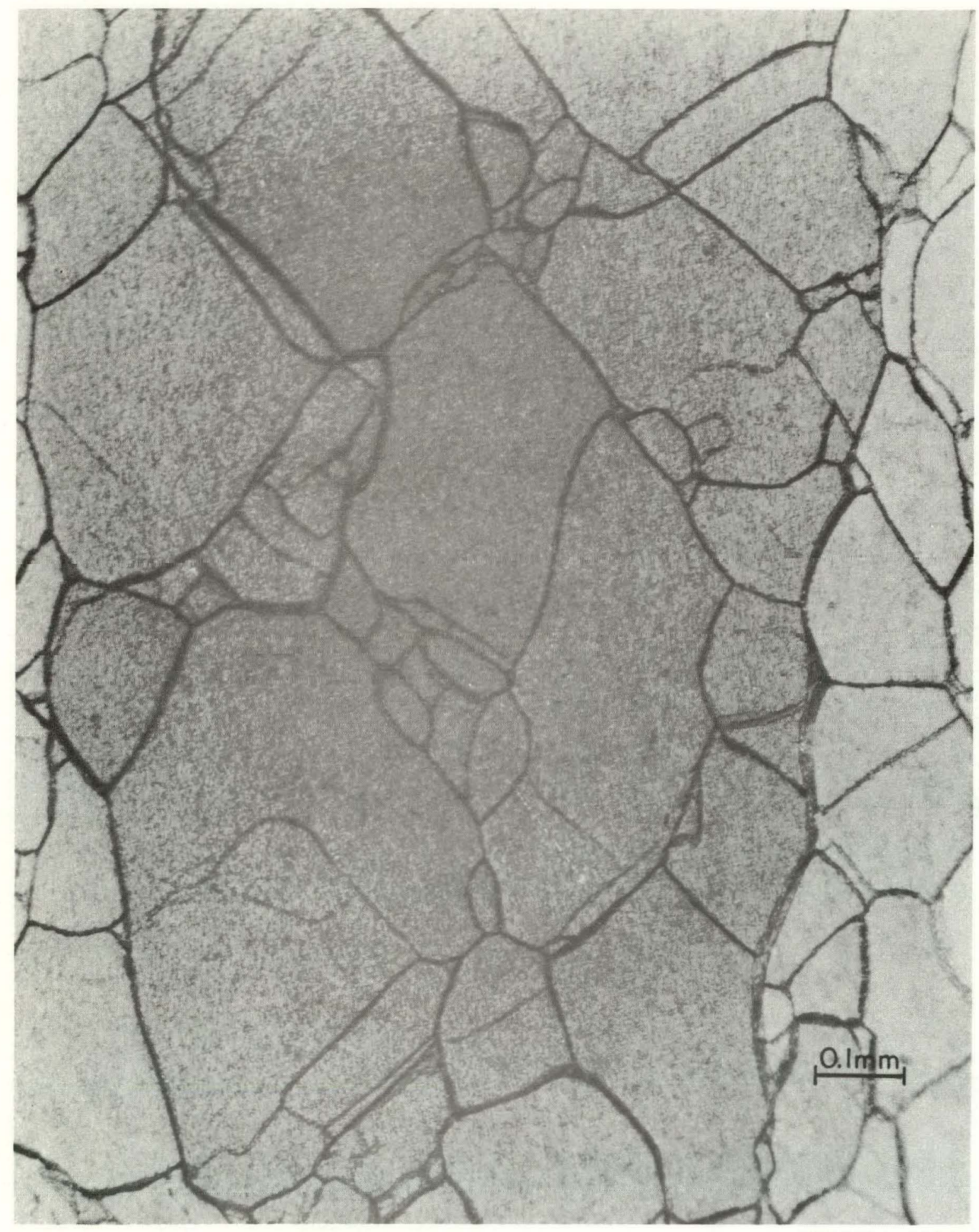

XBB7012-5393

Figure 19. <100> crystal deformed at $700^{\circ} \mathrm{C}$ and $200 \mathrm{psi}$. 


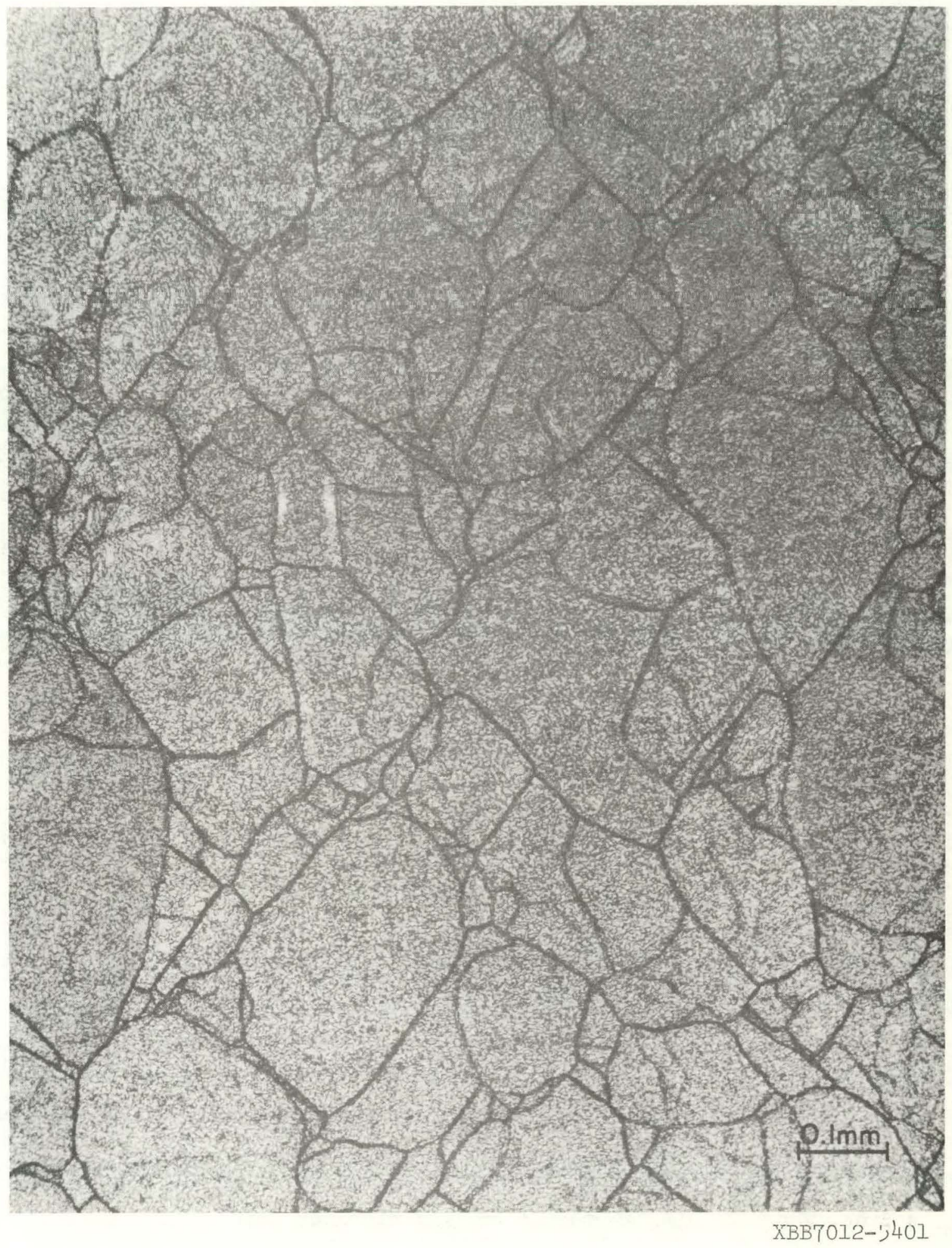

Figure 20. <100> crystal deformed at $700^{\circ} \mathrm{C}$ and 250 psi. 
subsequent photomicrographs the compression axis is horizontal. The relationship between subgrain diameter and applied stress is apparently similar to that observed for metals in that the subgrain size decreases with increasing stress. Using the linear intercept method, estimates of the subgrain diameter $\delta$ at various stress levels were obtained from <100> crystals deformed at $700^{\circ} \mathrm{C}$ and are plotted as dimensionless ratios $\delta / b$, where $\mathrm{b}$ is the Burgers vector, vs. the dimensionless stress function $\frac{\sigma}{G}$ in Fig. 21. The calculated slope of the line through the data points is -0.93 in good agreement with the experimental observation for metals that subgrain diameter is proportional to the -1 power of the applied stress.

The same,trend is observed for $\langle l l l\rangle$ crystals deformed at $700^{\circ} \mathrm{C}$ and stresses of 150, 200 and 250 psi, shown in Figs. 22-24, respectively. Plots similar to Fig. 21 showed a similar reciprocal relationship between subgrain diameter and applied stress for <lll> crystals. Of possibly greater significance, however, is the similarity between the micrographs of $\langle l l l\rangle$ crystals and those for $\langle 100\rangle$ crystals at comparable stresses; the observed subgrain diameters are substantially the same. The great differences observed in length of primary creep period for the two orientations would suggest corresponding large differences in development of microstructure. Yet a comparison of Figs. 22-24 with Figs. 17-20 indj.cates that the development of subgrains is substantially the same for both orientations. It is thus suggested that whatever differences occur to cause the observed variation in behavior probably are to be found on a finer scale of substructure than that observed here. That well defined subgrains do form during creep of LiF single crystals is yet another piece of evidence that creep in this system is 


$$
-45-
$$

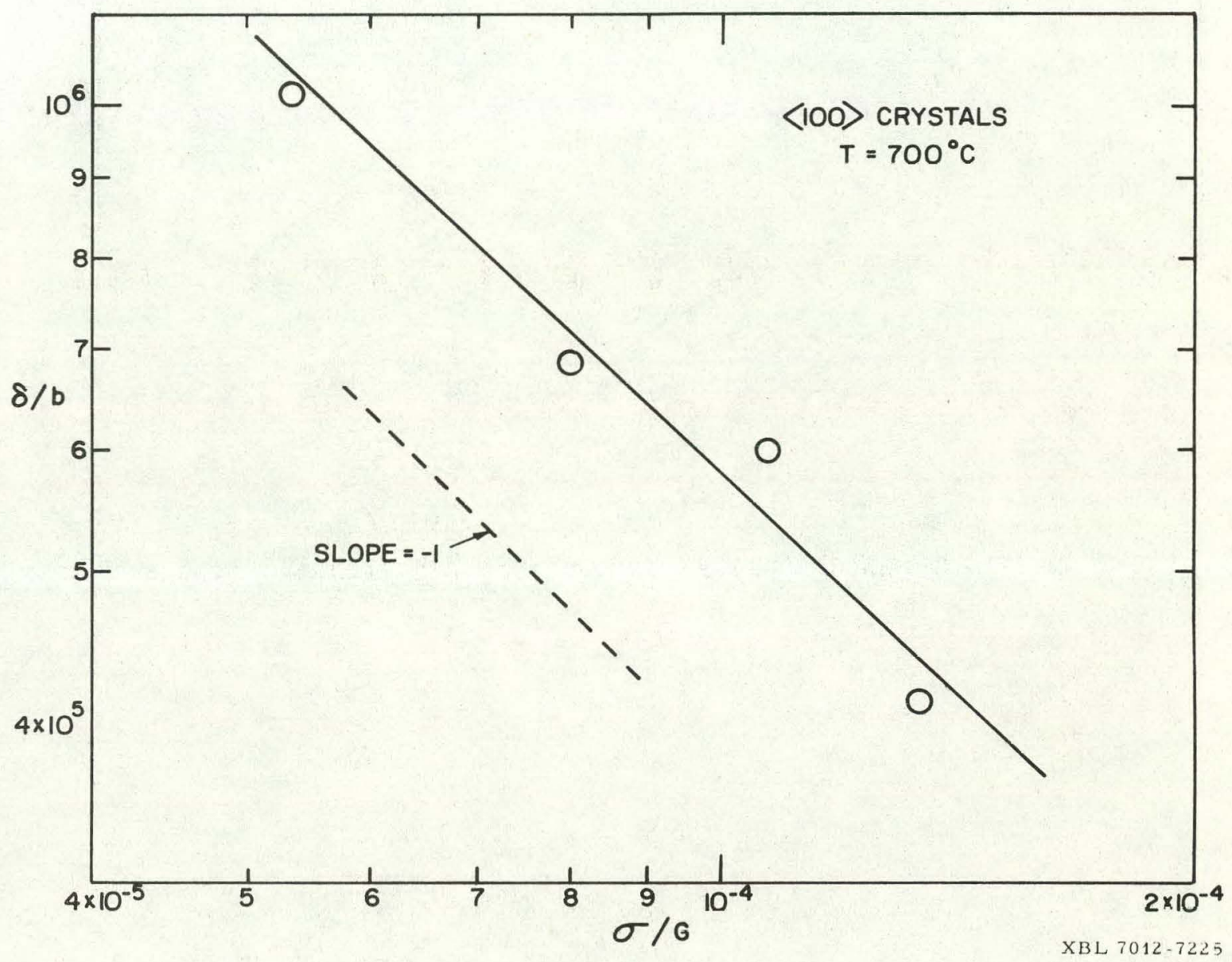

Figure 21. Sügrain diameter vs. normalized stress for $\langle 100\rangle$ crystals. 


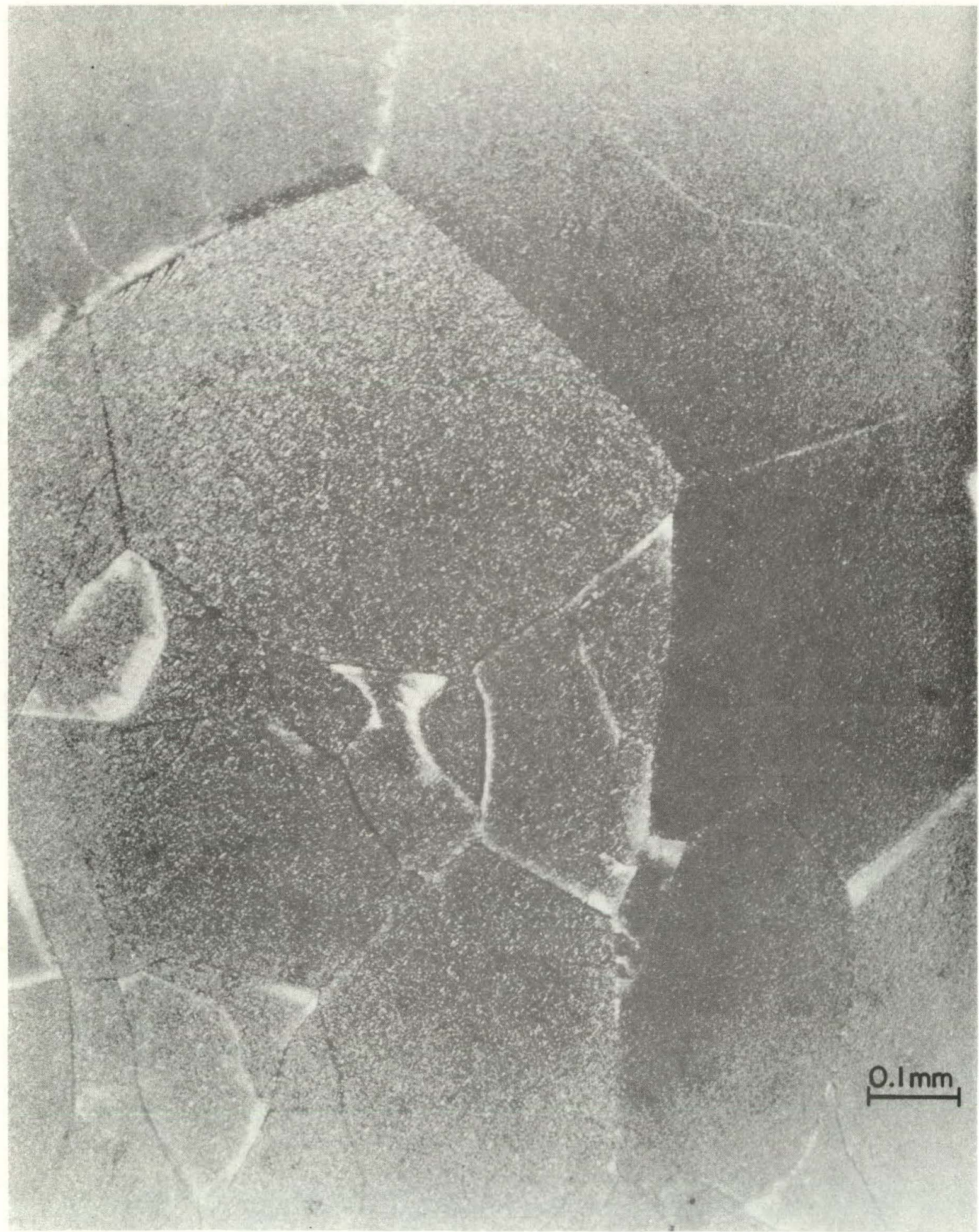

XBB7012-5396

Figurc 22, <Ill> crystal deformed at $700^{\circ} \mathrm{C}$ and 150 psi, 


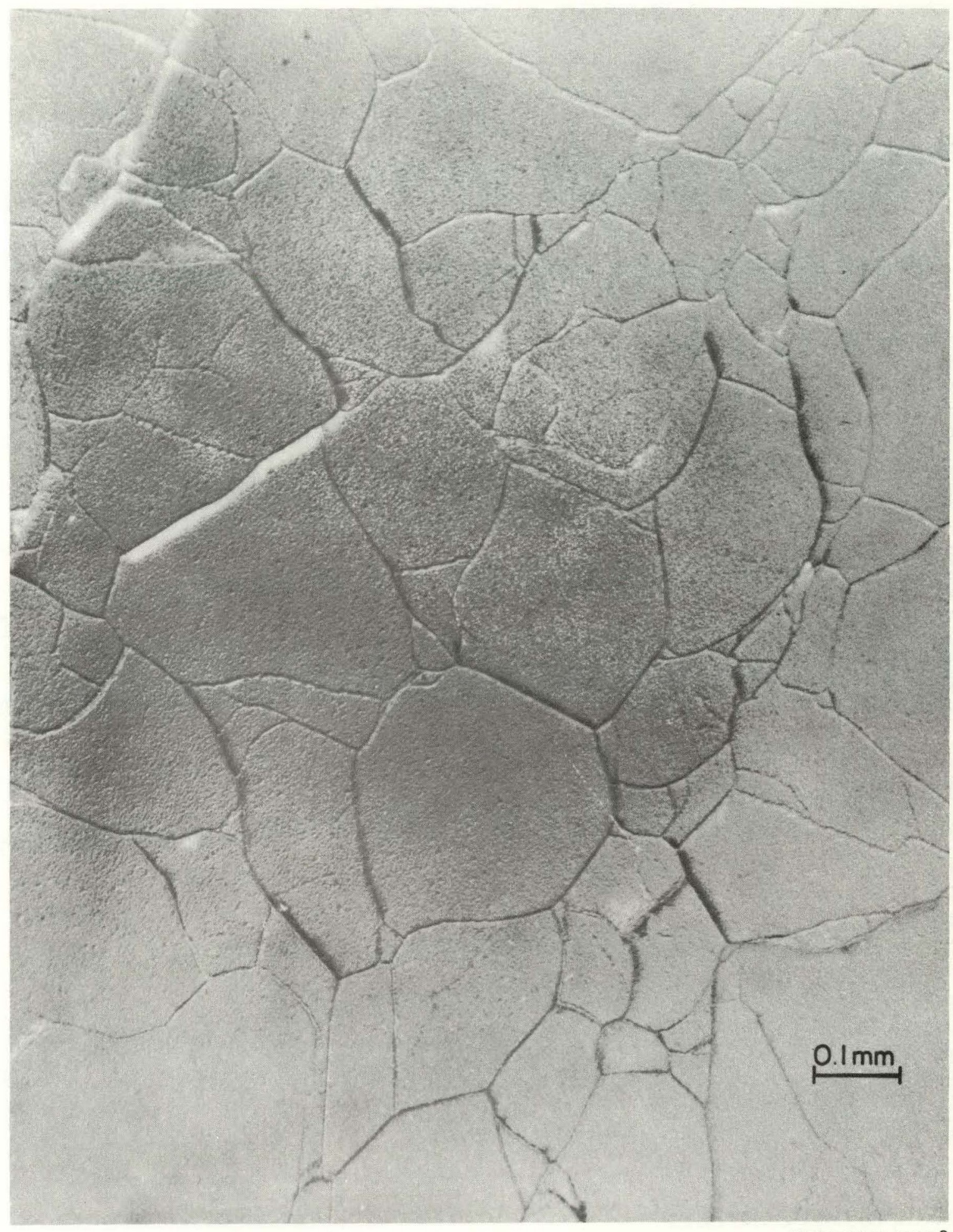

XBB7012-5398

Figure 23. <ll1> crystal deformed at $700^{\circ} \mathrm{C}$ and $200 \mathrm{psi}$. 


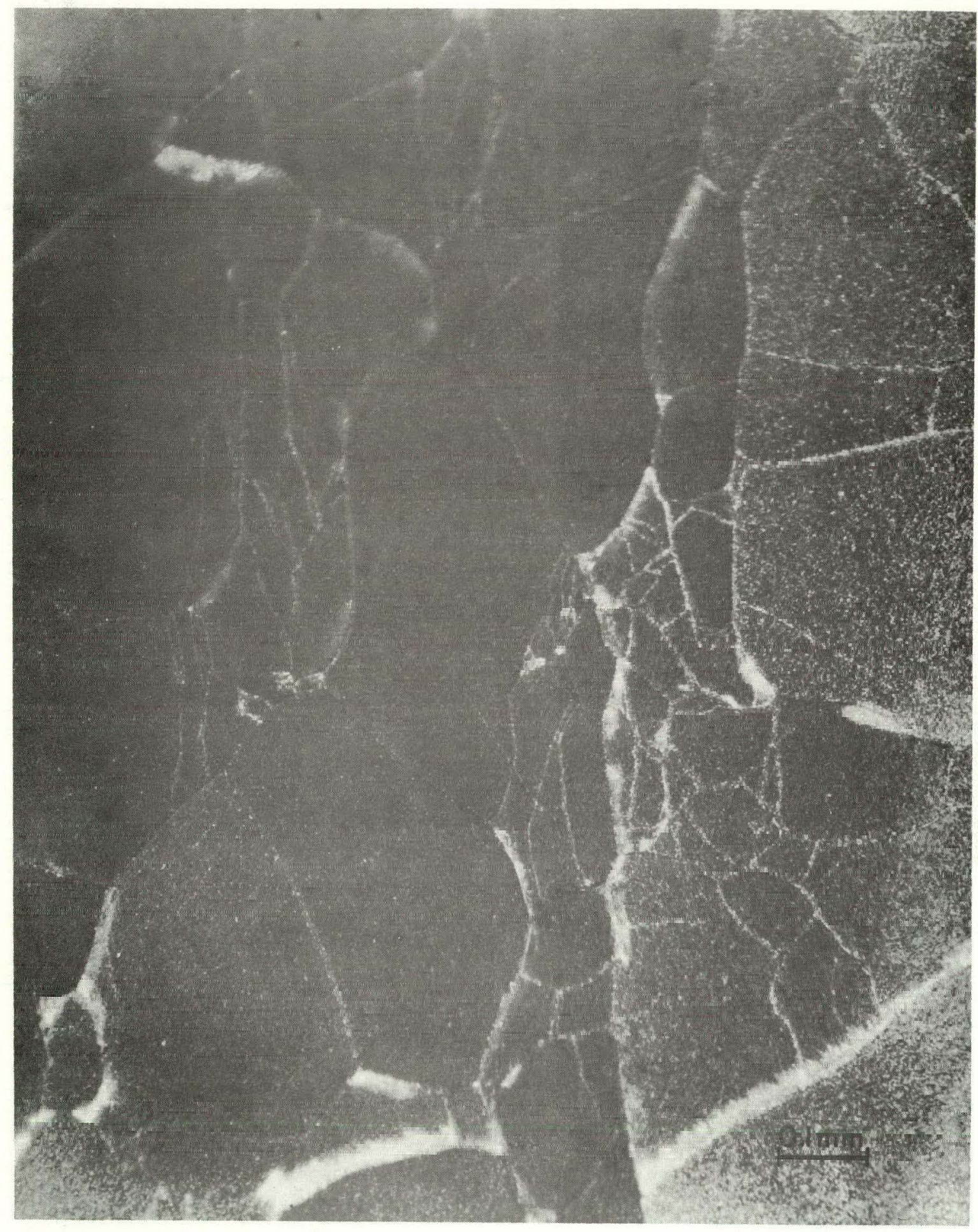

XBB7012-5391

Figure 24. <ll1> crystal deformed at $700^{\circ} \mathrm{C}$ and $250 \mathrm{psi}$. 
controlled by a dislocation climb mechanism. ${ }^{2}$ A particularly clear example of how the creep substructure may develop from slip bands introduced early in the deformation process is provided in Fig. 25. The region shown, near the end of a $\langle 100\rangle$ crystal deformed at $650^{\circ} \mathrm{C}$ and 200 psi, suggests that $\{110\}$ slip bands may provide the framework for subgrain boundaries which develop here predominantly at angles of $45^{\circ}$ to the stress axis (horizontal). 


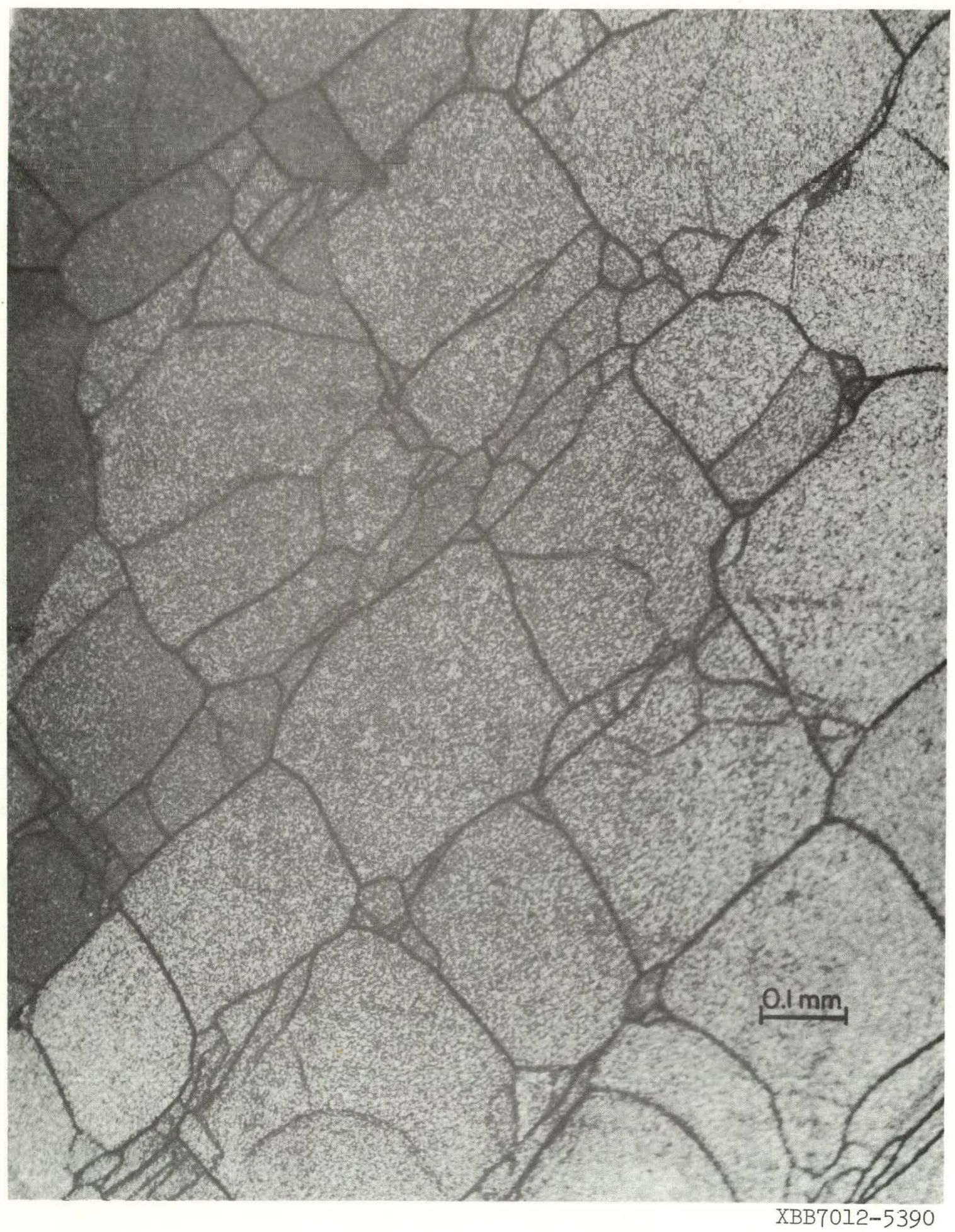

Figure 25. <100> crystal deformed at $650^{\circ} \mathrm{C}$ and $200 \mathrm{psi}$. 


\section{CONCLUSIONS}

1. The creep deformation of LiF single crystals is characterized by extended primary creep for crystals in <100> orientation with strains of 0.20 or more required for the establishment of steady-state creep. In contrast, crystals deformed in <lll> orientation reach steady-state conditions rapidly with primary creep strains of 0.05 or less required. Despite the difference in primary creep behavior for the two orientations, steady-state creep rates at corresponding stresses and temperatures are within a factor of two, with $\langle 100\rangle$ crystals having the higher rate.

2. The stress dependence of the steady-state creep rate was determined to be in the form of a power law for crystals of both $\langle 100\rangle$ and $<I l l>$ orientations, and impurity concentrations up to $300 \mathrm{ppm}$, with the stress exponent $n$ ranging from 3.1 for $<111\rangle$ crystals to 4.1 for $<100\rangle$ crystals. The effect of reducing the initial length/thickness ratios of the specimens from the normal $1.5-2.0$ to cube proportions $(l / t=1.0)$ appears to be a uniform decrease in steady-state strain rate without changing the stress exponent.

3. The activation energy for creep was determined to be $53 \pm 7$. $\mathrm{kcal} / \mathrm{mole}$ over the temperature range considered, regardless of crystal orientation or purity. This compares favorably with the activation energy for lattice diffusion of the fluorine ion in LiF, $50.7 \mathrm{kcal} / \mathrm{mole}$.

4. Attempts to determine the stress exponent and activation energy by the incremental technique were unsuccessful for $\langle 100\rangle$ crystals. The structural changes accompanying the long primary creep period apparently contribute to the large amount of scatter and non-reproducibility observed for that orientation. In contrast <lll> crystals responded 
accurately to the incremental technique and gave results in good agreement with values for $\mathrm{n}$ and $Q_{c}$ obtained from isothermal and constant stress tests.

4. Well developed subgrains were observed in both $\langle 100\rangle$ and $\langle 111\rangle$ crystals. The subgrain diameter, determined from optical microscopy, was found to vary inversely with the applied stress in agreement with results for many metals.

5. When formulated in terms of the dimensionless parameters $\frac{\dot{\varepsilon} \mathrm{kl}}{\mathrm{DGb}}$ and $\frac{\sigma}{G}$, the results for LiF single crystals fall in the range observed for metals when creep is dependent upon a dislocation climb process. The results thus suggest that the creep of LiF single crystals, over the range of experimental variables encountered here, is probably similar to that observed for many metals, and is dependent upon a dislocation climb process. 


\section{ACKNOWLEDGMENTS}

The author wishes to thank Professor Joseph A. Pask, who was the thesis supervisor, for his continued support, advice and encouragement through the course of this work. Additional appreciation is expressed to Professor. John Dorn for helpful discussions, to Bill Bullis and Jack Wodei for assistance with the construction of the experimental apparatus, and to John Sherohman for help in running the tests and reducing the data. Finally, deepest gratitude is expressed to mife Andrea for her patience and support.

This work was supported through the Inorganic Materials Research Division of the Lawrence Radiation Laboratory by the United States Atomic Energy Commission. 


\section{REFERENCES}

1. A. K. Mukherjee, J. E. Bird and J. E. Dorn, "Creep of Metals at High Temperatures," Trans. A.S.M. 61 697-698 (1968).

2. A. K. Mukherjee, J. E. Bird and J. E. Dorn, "Experimental Correlations for High Temperature Creep," UCRI-18526, Oct. 1968.

3. R. W. Christy, "Creep of $\mathrm{NaCl}$ and $\mathrm{NaBr}$ at High Temperature," Acta Met: $4,[5], 441-443(1956)$.

4. Ya. E. Geguzin, V. L. Robets and A. A. Chernyshan,"Creep of $\mathrm{NaCl}$ and KCl Single Crystals at Temperatures Near the Melting Point and Under Small Loads," Sov. Phys. Sol. State 5 [7] 1387-1392 (1964).

5. B. Ilschner and B. Reppich, "Das Kriechen von $\mathrm{NaCl}$ Einkristallen bei 500 bis $750^{\circ} \mathrm{C}, "$ Phys. Stat. Sol. $\underline{3}$ [10] 2093-2100 (1963).

6. W. Blum and B. Ilschner, "fber das Kriechverhalten von $\mathrm{NaCl}$ Einkristallen," Phys. Stat. Sol. 20 [2] 629-642 (1967).

7. F. Schuh, W. BIum and W. Ilschner, "Steady-State Creep Rate, Impurities and Diffusion in the Rock-Salt Structure," Proc. Brit. Ceram. Soc: №. 15 143-156 (1970).

8. W. D. Kingery and E. D. Montrone, "Diffusional Creep in Polycrystalline NaCl," J. Appl. Phys. 36 [8] 2412-2413 (1965).

9. P. E. Burke, "High Temperature Creep of Polycrystalline $\mathrm{NaCl}, "$ SU-DMS-68-T-59 (Ph.D. Thesis), Stanford University (1968).

10. P. LeComte, "Creep in Rock Salt," J. Geology 73 [3] 469-484 (1965).

11. R. W. Christy, "Creep of AgBr at High. Temperature," Acta Met. 2 [3] 284-295 (1964).

12. W. R. Cannon and O. D. Sherby, "High-Temperature Creep of $\mathrm{NaCl}-\mathrm{KCl}$ Solid-Solution Alloys," J. Am. Ceram. Soc: 53 [6] 346-349 (1970). 
13. D. R. Cropper and T. G. Langdon, "Creep of Polycrystalline LiF," Phil. Mag. 18 [156] 1181-1192 (1968).

14. V. I. Belekhtin and A. N. Bakhtibaev, "Durability and Creep of Ionic Single Crystals," Sov. Phys. Sol. State, 12 [2] 338-340 (1970).

15. C. O. Hulse, S. M. Copley and J. A. Pask, "Effect of Crystal Orientation on Plastic Deformation of Magnesium Oxide," J. Am. Ceram. Soc. 46 [7] 317-323(1963).

16. 0. D. Sherby, "Creep of Polycrystalline Alpha and Beta Thallium," Trans. Am. Inst. Min. Metal. Engrs. 212 [5] 708-715 (1958).

17. W. D. Scott and J. A. Pask, "Deformation and Fracture of Polycrystalline Lithium Fluoride," J. Am. Ceram. Soc. 46 [6] 284-293 (1963).

18. T. G. Langdon and J. A. Pask, "The Mechanism of Creep in Polycrystalline Magnesium Oxi de," Acta Met: 18 [5] 505-510 (1970).

19. S. Hart, "The Temperature Dependence of the Elastic Compliances of Some Alkali Halides," Brit. J. Appl. Phys. (J. Phys. D) Ser. 2 I [10] 1285-1289 (1968).

20. S. M. Copley and J. A. Pask, "Plastic Deformation of MgO Single Crystals up to $1600^{\circ} \mathrm{C}, " \mathrm{~J}$. Am. Ceram. Soc. 48 [3] 139-146 (1965).

21. R. B. Day and R. J. Stokes, "Mechanical Behavior of Magnesium Oxide at High Temperatures," J. Am. Ceram. Soc. 47 [10] 493-503 (1964).

22. R. B. Day and W. A. Johnstan, "Mechanical Behavior of Lithium Fluoride at High Temperatures," J. Am. Ceram. Soc. 52 [11] 595-599 $(1969)$.

23. F. R. N. Nabarro, "Deformation of Crystals by the Motion of Single Ions," Report of a Conference on Strength of Solids, p. 75, Royal 
Society, London (1948).

24. c. Herring, "Diffusional Viscosity of a Polycrystalline Solid,"

J. Appl. Phys. 21 [5] 437-445 (1950).

25. R. L. Coble, "A Model for Boundary Diffusion Controlled Creep in Polycrystalline Materials," J. Appl. Phys. 34 [6] 1679-1682 (1963).

26. J. Weertman, "Dislocation Climb Theory of Steady State Creep," Trans. A.S.M. 61 681-694 (1968).

27. J. Weertman, "Steady-State Creep Through Dislocation Climb," J. Appl. Phys. 28 [3] 362-364 (1957).

28. R. Chang, "Dislocation Theories of the High Temperature Creep of Crystalline Solids," The Physics and Chemistry of Ceramics, 275-285, New York; Cordon and Breach (1963).

29. H'. R. N. Nabarro, "Steady-State Diffusional Creep," Phil. Miag. 16 [140] 231-237. (1967).

30. R. C. Gifkins, "Transitions in Creep Behavior," J. Mat. Sci, 5 [2] $156-165$ (1970).

31. M. Eisenstadt; "Nuclear Magnetic Relaxation in LiF at High Temperatures," Phys. Rev. 132 [2] 630-635 (1963).

32. T. G. Stoebe and R. A. Huggins, "Measurement of Ionic Diffusion in Lithium Fluoride by Nuclear Magnetic Resonance Techniques," J. Mat. Sci. 1 [2] 117-126 (1966).

33. Y. Haven, "The Ionic Conductivity of Li-Halide Crystals," Rec. Trav. Chim. Pays-Bas 69 [11] 1471-1489 (1950). 


\section{LEGAL NOTICE}

This report was propared as an account of Government sponsored work. Neither the United States, nor the Commission, nor any person acting on behalf of the Commission:

A. Makes any warranty or representation, expressed or implied, with respect to the accuracy, completeness, or usefulness of the information contained in this report, or that the use of any information, apparatus, method, or process disclosed in this report may not infringe privately owned rights; or

B. Assumes any liabilities with respect to the use of, or for damages resulting from the use of any information, apparatus, method, or process disclosed in this report.

As used in the above, "person acting on behalf of the Commission" includes any employee or contractor of the Commission, or employee of such contractor, to the extent that such employee or contractor of the Commission, or employee of such contractor prepares, disseminates, or provides access to, any information pursuant to his employment or contract with the Commission, or his employment with such contractor. 
TECHNICAL INFORMATION DIVISION
LAWRENCE RADIATION LABORATORY

UNENCE RADIATION LABORATO
UNIVERSITY OF CALIFORNIA
BERKELEY, CALIFORNIA 94720 